\title{
O perfil dos jovens colaboradores para o processo de profissionalização e descentralização da empresa
}

\author{
João Carlos Leonardi \\ Faculdade Antonio Meneghetti (AMF) \\ Estela Maris Giordani \\ Universidade Federal de Santa Maria (UFSM) \\ Faculdade Antonio Meneghetti (AMF)
}

\begin{abstract}
Resumo: Este trabalho problematiza a relação do trabalho e da formação dos jovens em um processo de profissionalização e descentralização da gestão empresarial como forma de garantir a manutenção dos principais valores e referências do líder empreendedor, pois a empresa deve ter a sua identidade (MENEGHETTI, 2007, 2010). Fundamentado em Meneghetti (2003, 2005, 2007, 2009), Schiessl e Sarriera (2004), Câmara e Sarriera (2001), Martins (1997), Borges e Coutinho (2010), Morin, Tonelli e Pliopas (2007) discute-se o problema do jovem e a sua relação com o trabalho. Trata-se de um estudo de caso de cunho exploratório que considera as variáveis quali-quantitativas. Os dados foram coletados por meio de um questionário com questões abertas e fechadas, aplicado a 32 jovens de uma empresa do setor de construção civil do estado de São Paulo. O objetivo foi compreender os aspectos do modo de pensar destes jovens antes e depois do ingresso na empresa e também identificar se tais características atuais estão em consonância com os valores da empresa em que trabalham, tendo em vista que esta deseja investir em um programa de formação do tipo life long learning. Os resultados demonstram que as características principais dos jovens indicam a possibilidade de mudanças para a renovação da empresa, a gestão meritocrática e a profissionalização da equipe. Conclui-se que os jovens possuem identidade com os valores da empresa.

Palavras-chave: pedagogia ontopsicológica, life long learning, formação do jovem.
\end{abstract}

\footnotetext{
Abstract: This paper discusses the relationship of work and training of young people in a process of professionalization and decentralization of business management as a way of maintainingthe core values and references of the company as an entrepreneurial leader must have theidentity (Meneghetti, 2007, 2010). Based on Meneghetti (2003, 2005, 2007, 2009), and Sarriera Schiessl (2004), House and Sarriera (2001), Martins (1997), Borges \& Coutinho (2010), Morin and Pliopas Tonelli (2007) discusses the problem of young people and theirrelationship to work. This is a case study that considers the exploratory qualitative and quantitative variables. Data were collected through a questionnaire with open and closed questions, applied to 32 young people from a company in the construction of the state of Sao Paulo. The goal was to understand the aspects of thinking of these young peoplebefore and after joining the company and also to identify whether these features are in line with current values of the company they work for, considering that it wishes to invest in atraining program type of life-long learning. The results show that the main characteristics of young people indicate the possibility of

LEONARDI, João Carlos; GIORDANI, Estela. O perfil dos jovens colaboradores para o processo de profissionalização e desdentralização da empresa. Revista Saber Humano, Recanto Maestro, n. 3, p. 35-
} 34, 2013. 
changes to the renewal of the company meritocratic and professional management team. It is concluded that young people haveidentity with the company's values.

Key-words: onthopsychological pedagogy, life long learning, youth fostering.

\section{Introdução}

Esta pesquisa parte da premissa de que quando o líder centra-se no desenvolvimento de si mesmo, encontra transparência em sua mente, ou seja, o ponto em que tudo coincide e colhe com racionalidade a sua intuição. A partir de então é possível o investimento criativo em seu business (MENEGHETTI, 2010). E, segundo Barbieri (1998), o líder materializando em seu negócio o constante devir, ingressa em um contexto no qual os colaboradores exercem uma antítese necessária de evolução a qual mobiliza e gera um crescimento evolutivo e continuado. Conforme a autora, fundamental é a consciência do colaborador que entra no jogo do business vencedor do empresário. Este, por sua vez, é garantido se o seu business, que é conforme o seu core business, cresce continuamente e, propicia a empresa e colaboradores uma trajetória de crescimento. (MENEGHETTI, 2008; BAGGIO, 2010).

O que motivou o autor à realização da pesquisa foi a experiência profissional do mesmo, que é empresário e administrador de uma empresa do ramo da construção civil e a evidência de que, depois de certo estágio, para que a empresa continue crescendo de forma sustentável e tenha longevidade, é inevitável que o empresário tenha a maturidade e desprendimento para conduzir a profissionalização e a descentralização da gestão empresarial. Para isso, é imprescindível agregar os valores humanos individuais e formar uma equipe que esteja em identidade e utilitarismo funcional com a identidade da empresa. Tendo essa premissa, a equipe pode conduzir a operação estabelecendo assim uma mediação coincidente com a filosofia base da empresa. O empresário, portanto, pode dedicar-se à condução estratégica e especialmente à formação e desenvolvimento da sua equipe que o ajudará na condução e longevidade do negócio, promovendo assim, a renovação organizacional. Este é, conforme Araújo ${ }^{9}$, o terceiro ciclo de vida de uma organização - o empreendedorismo e o empresariamento são respectivamente o primeiro e o segundo níveis. Ainda segundo o autor: ser um empreendedor de sucesso só é possível para poucas pessoas que conseguem transformar uma ideia em um negócio. Qualificar-se como um empresário é algo que poucos empreendedores conseguem. Porém, o grande desafio das empresas está no terceiro ciclo, a profissionalização e descentralização da gestão, ou seja, a renovação empresarial.

Percebeu-se, mediante a experiência empírica ao longo do tempo, como empresário e executando obras que favoreceram o contato direto com diversos líderes e diretores de empresas, possibilitando conhecer suas trajetórias e acompanhar uma parte de suas histórias, que: a) se esta passagem não acontece, a condução da empresa fica pesada e desgastante para o líder, que se desmotiva absorvido pelo operacional sem poder se concentrar nas questões estratégicas e isto não se sustenta por muito tempo; b) caso esta passagem não seja executada com as pessoas adequadas ou, implementada de forma equivocada, os resultados certamente não serão bons e podem

\footnotetext{
${ }^{9}$ Conforme anotações pessoais de palestra realizada pelo Professor José Leonardo de Araujo sobre Liderança no Encontro Anual do Paex, outubro/2008 na Fundação Dom Cabral em Nova Lima-BH.
}

LEONARDI, João C.; GIORDANI, Estela M. O perfil dos jovens colaboradores para o processo de profissionalização e descentralização da empresa. Revista Saber Humano, Recanto Maestro, n. 3, p. 3567, 2013. 
inclusive comprometer a continuidade da empresa; c) se esta passagem é bem conduzida, o crescimento da empresa é potencializado, produzindo novos desafios e necessidades para a organização que exigirão novos conhecimentos, novas habilidades e, consequentemente, desenvolvimento da equipe ou novas pessoas, uma constante renovação organizacional.

O perigo constante é que o empreendedor, com a experiência e conhecimento adquiridos na construção do negócio, desenvolva seus "pré-conceitos e vícios" particulares. E, assim, o envolvimento emocional de suas preferências obscurece sua capacidade crítica de poder analisar com frieza e isenção necessária a condução da empresa e a escolha dos seus principais colaboradores. Além disto, por mais capacitado, empenhado e dedicado que o líder seja, chega a um ponto em que constata que não consegue mais controlar toda a operação com a equipe que o acompanha e toma consciência que a empresa cresceu mais do que sua capacidade de ação. Com as dimensões que o negócio alcançou o líder tem que transferir parte do poder decisório de assuntos que julga importante para terceiros e o controle da operação foge de suas mãos, porém sabe que as consequências destas decisões podem ser perigosas ou podem comprometer todo o negócio. Em muitos casos, em vez de fonte de motivação, a empresa passa a ser um peso sobre o líder. Entra em cena o medo e a insegurança.

Neste estado em que a mente permanece ofuscada e presa aos hábitos construídos, o líder começa a experimentar uma sensação de "perda", pois tem que começar a transferir o poder decisório de coisas que julga importante para terceiros e o "controle" de algumas partes foge de suas mãos, mas sabe que é ele próprio quem vai arcar com todas as conseqüências se o resultado não for satisfatório. Vê-se assim, preso e consumido pelo seu massificante cotidiano e percebe-se incapaz de conduzir a empresa a alcançar novos patamares e ingressar em um contexto de evolução criativa.

Neste ponto, muitos empresários tomam a decisão de parar de crescer acreditando que assim poderão ter mais tranqüilidade e estabilidade. Acreditam que já estão consolidados no mercado e possivelmente já estão conseguindo resultados financeiros satisfatórios. Porém esta decisão comprometerá a empresa no médio prazo, pois uma parte da equipe perceberá a estratégia e pela falta de motivação e possibilidade de crescimento a abandonarão e permanecerão os menos capacitados e acomodados ao lado do líder. Além disto, certamente alguns concorrentes continuarão a se aperfeiçoar e conquistarão expressivas vantagens competitivas. Outros, neste momento, optam por vender a empresa. Contudo, se o negócio nasceu da intuição do líder é nele que ele deve investir, pois a garantia e segurança da empresa é a sua inteligência; é ele a referência de sua empresa (MENEGHETTI, 2008, 2010; BAGGIO, 2010; FOLETTO, 2011; ARGENTA, 2011).

Impulsionado por este contexto, colocou-se os seguintes questionamentos: a) como fazer a passagem de um negócio que é dependente do líder para todas as decisões importantes, para uma empresa com gestão profissionalizada?; b) como constituir uma equipe com as competências, habilidades e atitudes adequadas às funções que vão exercer e que sejam comprometidas e alinhadas com a filosofia do líder empreendedor? Acredita-se que uma parte da resposta a estes questionamentos derive do investimento na formação de tipo life long learning do líder e dos colaboradores.

Partindo destas reflexões, a pesquisa desenvolvida se propôs a conhecer a equipe de jovens de uma

LEONARDI, João C.; GIORDANI, Estela M. O perfil dos jovens colaboradores para o processo de profissionalização e descentralização da empresa. Revista Saber Humano, Recanto Maestro, n. 3, p. 3567, 2013. 
empresa da construção civil do estado de São Paulo a fim de identificar se existe identidade e utilitarismo funcional com a empresa. Deste modo, tratou-se de conhecer o posicionamento de jovens antes e depois de estarem trabalhando na empresa e a identidade destes jovens com a identidade da empresa.

$\mathrm{E}$, os objetivos específicos foram assim definidos: a) identificar como os jovens se posicionam frente às transformações de suas vidas e como se percebem antes e depois de estarem trabalhando na empresa; b) traçar o perfil e as características dos jovens da empresa a fim de identificar se a forma mentis (mentalidade) deles possui a identidade com os seus valores. A pesquisa foi realizada com um grupo de 32 jovens por meio de um questionário com questões abertas e fechadas e a abordagem foi quali-quantitativa em ciências sociais aplicadas (HAIR, 2007).

\section{A inserção do jovem no mercado de trabalho}

O mercado de trabalho sempre está em constante transformação, exigindo dos trabalhadores o desenvolvimento de novos conhecimentos, novas competências e habilidades. Mudanças estruturais nos sistemas produtivos para fazer face à globalização, assim como a consequente busca de competitividade pelos agentes econômicos têm levado a um processo de redefinição continuada do mercado de trabalho. De fato, conforme indica Schaefer (2011) em sua pesquisa, entrevistando profissionais recrutadores $\mathrm{e}$ empresários, a maior dificuldade no mercado de trabalho para os jovens não é a falta de espaço ou ocupação, visto que, atualmente houve a expansão da demanda de mão-de-obra. A pesquisa evidencia que a precária formação a qual não correlaciona conteúdos teóricos com aplicação prática é um dos principais motivos da dificuldade de inserção do jovem no mercado de trabalho. Não se trata do mercado não absorver os que ingressam no mercado de trabalho. As taxas de desocupação elevadas, para os mais jovens, devem-se muito mais à falta de preparo do que à efetiva falta de vagas.

O movimento da Comunidade Europeia (2000), tendo em vista a necessidade cada vez maior de qualificação apropriada do mercado, tem apostado no conceito de aprendizado ao longo da vida, life long learnig ${ }^{10}$. E isso implica em investir na formação dos jovens do ponto de vista das políticas públicas, bem como no contexto das organizações, e promover a qualificação necessária para os jovens tornarem-se profissionais que consigam responder à demanda de competitividade das organizações. O lema atual é "investir na juventude, combater a crise de empregos" "11. Também, conforme Meneghetti (2007, p. 11):
A velocidade das modificações socioeconômicas impõe uma atualização contínua das competências e habilidades. É necessária uma formação do tipo life long learning. Para ser líder no contexto global não se pode mais permanecer esclerosado em papéis, funções e modalidades operacionais, deve-se confrontar com cenários mutáveis (MENEGHETTI, 2007, p. 11).

De fato são os jovens são os mais diretamente afetados pelo contexto adverso do mercado de trabalho, uma vez que, normalmente, já estão em situação de desvantagem devido às suas características específicas, como a falta de experiência e a busca por oportunidades.

\footnotetext{
${ }^{10}$ COMISSÃO DAS COMUNIDADES

EUROPEIAS. Documento de Trabalho dos

Serviços da Comissão. Memorando sobre

Aprendizagem ao Longo da Vida. Bruxelas, 30/10/2000.

${ }^{11} \mathrm{http}: / / w w w . l e t r a s e l u c r o s . c o m . b r / 2010 / 12 /$ investir -na-juventude-para-combater-a-crise-de-empregos/
} 
Conforme Rocha (2008), a dedicação exclusiva à escola é predominante até os 18 anos, a partir de quando o trabalho assume esse papel. A combinação de trabalho e estudo cresce paulatinamente a partir dos dez anos, com a contribuição maior do trabalho em áreas rurais, e atinge o seu pico aos 17 anos. Assim, a mudança drástica em termos de entrada no mundo do trabalho se dá entre 17 e 19 anos, aumentando mais fortemente a partir dessa idade.

Entretanto, nos últimos anos temse evidenciado que os jovens em grande parte estão buscando se qualificar para o mercado de trabalho, ingressando em cursos de nível superior. Schiessl e Sarriera (2004) destacam que a necessidade de preparação dos jovens para o exercício de qualquer atividade na sociedade torna-se requisito indispensável. Logo, estudar e preparar-se para uma carreira profissional é, atualmente, tarefa fundamental para aqueles que conseguem concluir o ensino médio e ingressar em uma universidade. Mais do que uma oportunidade é uma necessidade. Escolher uma profissão consiste em definir o projeto de vida e o modo de conquistar a autonomia, o reconhecimento pessoal e a participação na sociedade através do trabalho.

Nesta perspectiva, para muitos jovens adultos, o fim de um curso universitário significa a promessa de uma nova fase de vida, marcada pelo início do exercício da profissão escolhida. Porém, um dos principais problemas com o qual os recém-formados se deparam é a dificuldade de ingressar no mercado de trabalho de suas profissões. Se há algumas décadas o diploma universitário era garantia para emprego bem remunerado ou boa colocação no mercado como profissionais autônomos, hoje a realidade é diferente. Se por um lado Teixeira e Gomes (2004) argumentam que há uma nítida redução no número de empregos oferecidos, pois as inovações tecnológicas transformaram profundamente o campo das ocupações profissionais. Por outro, observa-se que é necessário mudar o paradigma de compreensão da formação dos jovens, pois espera-se que o trabalhador seja mais flexível, apresentando maior repertório de habilidades e competências. $\mathrm{O}$ jovem precisa ser preparado para saber fazer todas as ações que envolvem o seu mericismo cotidiano, aprender a cuidar de si, de seu ambiente, de suas pequenas coisas, estas aprendizagens depois tornam-se elementares no setor competitivo (MENEGHETTI, 2009).

Percebe-se que a responsabilidade por desenvolver as competências que possibilitarão atender a essa demanda do mercado de trabalho tem ficado a cargo do indivíduo, que é visto como responsável tanto pelo seu sucesso quanto pelo seu fracasso. Portanto, a conquista de um espaço no mercado não depende apenas de um diploma, mas também de características pessoais, competências específicas, redes de relações e capacidade de ajustar-se a diferentes demandas de trabalho (DELORS et al, 2009). Conforme Meneghetti (2010) para o jovem ingressar no mercado de trabalho é indispensável cinco pontos: a) ter um diploma de ensino superior; b) saber ao menos uma língua estrangeira; c) saber operar o computador e a internet; d) especializar-se em um campo de interesse; e) aprender a falar em público.

Frente a essa nova realidade, é preciso questionar qual é a perspectiva dos jovens em relação à sua inserção no mercado de trabalho, bem como qual é a perspectiva dos empregadores? Isto é, o que as empresas esperam dos jovens que se apresentam à procura do trabalho? A transição da universidade para o mercado de trabalho pode ser caracterizada como um período exploratório no qual o jovem investiga as possibilidades existentes em sua profissão e procura experimentar-se em diferentes papéis. A qualidade da

LEONARDI, João C.; GIORDANI, Estela M. O perfil dos jovens colaboradores para o processo de profissionalização e descentralização da empresa. Revista Saber Humano, Recanto Maestro, n. 3, p. 3567, 2013. 
transição reflete, ao menos em parte, o grau de comprometimento do indivíduo com a profissão escolhida. Esse grau de comprometimento revela-se nas suas expectativas frente ao curso universitário, no seu envolvimento com as atividades de formação e nas suas atitudes de preparação para essa transição.

De acordo com Teixeira e Gomes (2004), em vários momentos da trajetória universitária os jovens reavaliam suas expectativas, reestabelecem objetivos e (alguns sim, outros não) planejam a sua transição. O que está implicado nessa transição, contudo, não é apenas a formação profissional ou a colocação no mercado de trabalho. Para muitos se trata de um movimento mais amplo de independência do meio familiar e de estabelecimento na vida adulta, movimento este que para a maioria dos estudantes inicia-se na adolescência e tem na escolha profissional e na experiência universitária momentos significativos. A conclusão do curso universitário, portanto, implica em uma reavaliação das escolhas realizadas, das experiências vividas até o momento e, também, uma antecipação do que está por vir, tanto em termos profissionais como não profissionais. Para os autores, a formação na universidade deve ser vista como algo que vai além dos conteúdos vistos em aula. Ela inclui, certamente, experiências de conhecer pessoas com idéias diferentes, de fazer contatos, de lidar com a competição e de conviver com adversidades entre colegas. Tais experiências trazem mudanças no âmbito pessoal e auxiliam na preparação para a vida profissional.

Para os jovens, a entrada no mercado de trabalho tornou-se uma etapa desejável, inescapável e definitiva, tanto para os homens como para as mulheres. Naturalmente, a conjuntura econômica e as características individuais determinam de forma mais direta a decisão de entrada e permanência dos jovens no mercado de trabalho, mas a mudança estrutural em relação à percepção do mundo do trabalho é inequívoca. Sarriera (2004) destaca que:

\begin{abstract}
A complexidade do mundo do trabalho reside, muitas vezes, em suas ações fragmentadas, plenas de criatividade e iniciativas que faz com que os ingressantes tenham uma impressão de estranheza, não encontrando pontos de referência, onde ancorar suas expectativas e suas experiências anteriores. (...) $\mathrm{O}$ iniciante não vai encontrar um nicho específico que lhe dê espaço para aplicar seus conhecimentos e competências decorrentes de sua formação em uma determinada disciplina. O desafio agora na dura realidade de cada dia é de como cruzar as várias disciplinas, tecendo os vários fios na solução de problemas intrincados (SARRIERA, 2004, p. 16).
\end{abstract}

Ainda conforme Sarriera (2004), hoje os jovens buscam empregos onde possam exercer suas competências técnicas, tecnológicas, cognitivas, sociais e afetivas. Querem contribuir para a construção do ambiente de trabalho que lhes permita evoluir, aperfeiçoar-se e desenvolverem-se continuamente como pessoas e profissionais. Entretanto, para que o jovem consiga construir uma identidade profissional, é preciso primeiramente que ele estabeleça uma identidade pessoal a partir de expectativas frente aos seus ideais, interesses e possibilidades. Nessa perspectiva, Sarriera (2004) considera a escolha profissional um fato socialmente significativo, uma vez que define a vida das pessoas, mesmo que provisoriamente, condiciona a sua inserção social, possibilita quadros de competência no nível da produção e favorece a integração do homem versus trabalho. A escolha profissional deve ser um meio que possibilite o desenvolvimento do autoconceito de cada jovem, à medida que este vai se modificando, a sua escolha profissional vai se tornando cada vez mais específica e delimitada.

A escolha profissional, portanto, possui uma importância fundamental para

LEONARDI, João C.; GIORDANI, Estela M. O perfil dos jovens colaboradores para o processo de profissionalização e descentralização da empresa. Revista Saber Humano, Recanto Maestro, n. 3, p. 3567, 2013. 
a vida dos jovens e sua inserção no mercado de trabalho, pois o trabalho representa na vida das pessoas um processo de amadurecimento, sendo o responsável pelo sentimento de satisfação pessoal ao longo da vida adulta. Sarriera (2004) analisa que, embora a escolha profissional seja uma responsabilidade individual, as consequências de sua decisão têm inúmeras implicações sociais, porque é um acontecimento que envolve, não apenas o jovem, mas toda a sociedade. Quanto maior o conhecimento do jovem sobre si mesmo e sobre o contexto do mercado de trabalho, maior será a possibilidade da escolha profissional satisfaze-lo.

Pais (1991) resume essa discussão apontando os fatores que exprimiriam essa dificuldade de inserção dos jovens no mercado de trabalho, a qual fortalece a insatisfação e as perspectivas para o futuro profissional: 1) a diminuição das oportunidades de empregos para os jovens, principalmente em decorrência da introdução de novas tecnologias, com as exigências de maior qualificação e experiência; 2) a significativa mobilidade ocupacional dos jovens, com a circulação por diversas situações seja de trabalho (formação, aprendizagem, precário, temporário, em tempo parcial, etc.), seja de emprego (desemprego, inatividade, emprego); 3) a precarização do trabalho juvenil seria acompanhada pela periferização dos jovens em torno do mercado de trabalho secundário, tanto em consequência da sua fraca especialização/qualificação, que os orientaria para o trabalho nos setores periféricos, quanto por uma preferência pelo trabalho "intermitente", antes de buscarem estabilidade e assumirem maiores responsabilidades; 4) o processo de seleção nas empresas, que basicamente consiste em suprir as necessidades destas, em detrimento das necessidades dos jovens trabalhadores, tendo em vista o máximo de aproveitamento da mão de obra, e o menor custo possível. Portanto, as recentes modificações nas estruturas produtivas, especialmente com a introdução de recursos tecnológicos, que afetam o perfil setorial do emprego, transformam as atividades profissionais, alteram o funcionamento do mercado de trabalho e modificam inclusive os modos de vida e por isso requerem um outro perfil de formação do jovem.

O perfil desejado hoje no mercado de trabalho é um profissional além de qualificado capaz de apresentar flexibilidade a fim de interagir no contexto de mobilidade, autonomia, capacidade de suportar contextos ou situações limites, permanente disponibilidade de aprendizagens novas, dentre outras. Sem uma formação elementar que considere os conhecimentos, as habilidades e atitudes diminuem as chances de sucesso dos jovens ao acesso e manutenção no mercado de trabalho no contexto da sociedade contemporânea.

Para Martins (1997), a experiência de trabalho e de vida da juventude operária, com a imagem de seus pais, de suas condições insatisfatórias de trabalho, faz com que os jovens elaborem negativamente a sua identidade em relação ao emprego e ao trabalho. Cada vez mais, amplas camadas da população juvenil passam por um período relativamente longo de indeterminação antes de ingressarem na vida adulta ou, pelo menos, da inserção profissional. Segundo a autora, o que se vê hoje é uma imagem da juventude marcada pela negatividade, que ressalta $o$ individualismo, o consumismo, a passividade, a falta de companheirismo e o afastamento das questões que afetam o conjunto dos trabalhadores. Nas análises sociológicas da juventude,
essa relação instrumental com o trabalho
tem sido explicada como decorrência da
mudança nos valores e nos modos de
regulação social que afetam a maneira

LEONARDI, João C.; GIORDANI, Estela M. O perfil dos jovens colaboradores para o processo de profissionalização e descentralização da empresa. Revista Saber Humano, Recanto Maestro, n. 3, p. 3567, 2013. 
pela qual o jovem é socializado e preparado para entrar no mundo do trabalho. As exigências de autonomia individual, o individualismo exacerbado e a valorização dos modos privados de consumo, constituiriam os elementos sociais básicos que orientam os jovens na elaboração das representações do emprego e do trabalho (MARTINS, 1997, p. 104).

É preciso considerar a existência de reações diferenciadas dos jovens diante do mercado de trabalho, buscando escapar da tendência de ver a juventude como um conjunto homogêneo. Neste contexto, conforme Teixeira e Gomes (2004), a inserção dos jovens no mercado de trabalho caracteriza-se por ser um momento de antecipação e não de realização de projetos, o que faz com que eles sintam-se um tanto sem referências para dar sustentação ao seu senso de identidade: não são mais estudantes, mas ao mesmo tempo não são ainda profissionais. Da mesma forma, não se consideram mais adolescentes, mas também não se percebem como propriamente adultos, mas numa condição de adultez emergente.

Segundo Câmara e Sarriera (2001), como tentativa de superar estes obstáculos que o mundo capitalista impõe ao jovem, é preciso primeiramente que este se identifique com a profissão que busca exercer e, mais do que isso, se identifique com a empresa onde irá trabalhar, construindo assim uma identidade profissional. Meneghetti (2010) salienta a importância do jovem trabalhar em uma empresa em que ele encontre identidade ideológica, visto que, se não for assim, não haverá um real crescimento pois em função da contraposição o jovem não constrói com a empresa e o seu projeto de vida. Por exemplo, o jovem, não deve trabalhar em uma empresa capitalista se ele possui uma ideologia comunista. Além disso, para o jovem é fundamental o savoir faire que é concebido como "inteligência centrada na ação específica de serviço à empresa e onde a pessoa é fundamental" (MENEGHETTI, 2009, p. 19).

Desta forma, para ingressar no mercado de trabalho o jovem deve: a) ter uma base econômica, que implica um saber fazer bem algo, isso exige um diploma, saber pelo menos uma língua estrangeira, usar o computador e a internet, especializar-se em um campo de interesse e aprender a falar em público; b) liberdade legal, que significa não ter nenhum tipo de atuação fora do que a lei prevê e não errar gravemente contra as leis e o Estado; c) ter pessoas de apoio que sejam inteligentes e o auxiliem a resolver os problemas. O autor ainda diz que "o jovem descobrirá que quanto maior for a contribuição qualificada que souber dar à empresa onde trabalha, maior será a correspondência de gratificação, sob todos os pontos de vista. Portanto, por meio do trabalho, ganha a excelência da própria dignidade, da sua autonomia econômica e da sua liderança" (MENEGHETTI, 2009, p. 20).

Meneghetti (2009) os três fatores que constituem o ponto crítico de todos os jovens empresários são: a) que o jovem quando adquire certo patamar de sucesso financeiro faz-se gratificar por meio de um exibir-se do quanto é bravo, contudo, pode cair em autossabotagem visto que, pode subestimar o vizinho, o Estado, as leis que poderão colocar-lhe em problemas; b) trabalhar em empresas de grandes capitais que oferecem vantagens para os jovens mas que em seguida são queimados ou destruídos dentro do jogo do mercado da economia nacional ou internacional; c) "a imaturidade do jovem no evento histórico de fortuna social" (p. 16).

Câmara e Sarriera (2001), também salientam que as empresas exigem um perfil idealizado de jovem, que se distância da realidade, dificultando a inserção dos jovens no mercado de trabalho. Nesta perspectiva, é preciso que

LEONARDI, João C.; GIORDANI, Estela M. O perfil dos jovens colaboradores para o processo de profissionalização e descentralização da empresa. Revista Saber Humano, Recanto Maestro, n. 3, p. 3567, 2013. 
algumas questões devam ser repensadas pelas empresas:

\begin{abstract}
Existe um candidato perfeito? É o solteiro ou aquele que precisa sustentar uma família? É aquele que teve um bom desempenho na escola ou aquele que soube comportar-se? É aquele que chegou ao fim de sua formação escolar básica ou aquele que não pôde concluí-la porque estava tendo suas primeiras experiências precoces de trabalho? Em que escola ele estudou? Ele tinha carteira assinada em seus primeiros empregos ou submeteu-se a condições de exploração? Onde vive? Onde viveu? Ele, misteriosamente, mesmo sendo jovem, é uma pessoa madura? (CÂMARA \& SARRIERA, 2001, p. 83).
\end{abstract}

Conforme destacam os autores, estas perguntas não estão escritas e suas respostas nunca são dadas de forma espontânea e direta. Talvez, seja mesmo necessário o empregador saber determinar um perfil que corresponda às exigências do crescimento da empresa e da pessoa do colaborador. Assim, fundamental é conhecer as diferentes potencialidades dos colaboradores e coordenar as pessoas de modo que seus talentos sejam realmente complementares. Para que ocorram transformações neste cenário, é preciso que sejam desenvolvidas, de forma mais ampla, aprendizagens que envolvem a temática do papel do mercado de trabalho para o crescimento das pessoas e das empresas, principalmente no que se refere ao desenvolvimento dos jovens, tanto profissionalmente como enquanto pessoas em processo de construção de si mesmas.

\section{encontrada.}

Erro! Fonte de referência não

O ambiente de trabalho é a variável que mais afeta o desenvolvimento das pessoas. Se esse ambiente não for propício ao crescimento do trabalhador, nada do que for feito será eficaz. Para a aquisição de conhecimento, é necessário que haja motivação por parte do aprendiz e que o trabalho tenha um significado na vida do jovem trabalhador.

De acordo com Morin, Tonelli e Pliopas (2007), para ter significado na vida dos jovens, o trabalho precisa ter as seguintes características: a) ter variedade e ser desafiador; b) possibilitar reconhecimento e apoio; c) trazer uma contribuição social e permitir um futuro desejável. As características que o trabalho deve ter são consoantes com os motivos que estimulam os jovens ao trabalho, sendo necessário haver boas condições de trabalho (horários convenientes, bom salário, preservação da saúde); d) oportunidade de aprendizagem contínua e realização adequada da tarefa; e) o trabalho deve ser estimulante, variado e com autonomia. Para as autoras, o trabalho quando faz sentido na vida dos jovens é feito de maneira eficiente, levando a um resultado útil para a empresa e para o próprio jovem. Borges e Coutinho (2010) destacam que o sentido é "a expressão mais subjetiva do sujeito, num conjunto de fatores biológicos, intelectuais e afetivos que "imprimem" sua particularidade, apresentando-se como uma categoria complexa" (p. 190). Assim, “(...) o sentido é muito mais amplo que o significado, pois o primeiro constitui a articulação dos eventos psicológicos que o sujeito produz frente uma realidade" (AGUIAR \& OZELLA, 2006, p. 226).

O significado, por sua vez, representa segundo Vigotski (1992), uma generalização ou um conceito, muitas vezes "dicionarizado", mais inflexível e em constante evolução sofrendo alterações quantitativas e externas de acordo com o momento histórico. Desse modo, os significados estabelecidos na esfera social são históricos e culturais.

No contexto atual dos jovens trabalhadores, os sentidos devem ser compreendidos como expressões sociais construídas a partir da vivência pessoal e dotados de emoções, sentimentos, contradições e ambivalências

LEONARDI, João C.; GIORDANI, Estela M. O perfil dos jovens colaboradores para o processo de profissionalização e descentralização da empresa. Revista Saber Humano, Recanto Maestro, n. 3, p. 3567, 2013. 
representativas na construção histórica do sujeito. Para Rocha (2008), o trabalho possui uma importância na vida dos jovens enquanto um valor cultural $\mathrm{e}$ econômico, tornando-se o formador das novas gerações. $O$ trabalho, na visão da autora, configura-se como uma necessidade decorrente das condições econômicas em que os jovens vivem com suas famílias, porém a valorização do trabalho é resultado de fatores culturais, ou seja, é um fator cultural que se impõe ao jovem com o tempo.

Contudo, há ainda, outro significado do trabalho que Rocha (2008) observa: o sentido de decisão e de afirmação. Os jovens querem trabalhar para se sentirem importantes dentro de sua família, mas, também, para poderem ter certa estabilidade financeira que lhes permitam o acesso a uma "gramática do gosto" "12, que é fundamental na construção de uma identidade jovem. Para Guimarães (2004), o trabalho passa a ser o centro das atenções dos jovens, quando estes começam a pensar e arquitetar planos para o futuro. A autora ainda salienta que a centralidade do trabalho para os jovens não advém dominantemente do seu significado ético (ainda que ele não deva ser de todo descartado), mas resulta da sua urgência enquanto problema; ou seja, o sentido do trabalho seria antes o de uma demanda a satisfazer as necessidades, interesses e urgências, pessoais e sociais.

Conforme Borges e Coutinho (2010), os jovens ao pensarem no mercado de trabalho, arquitetam seus projetos, alguns em conformidade com sua história de vida, outros buscam ressignificações, sendo todos os projetos construções dialéticas, singulares e não hegemônicas. Conforme Morin, Tonelli e Pliopas (2007), o trabalho assume na vida do trabalhador três sentidos principais: como dimensão individual, como

\footnotetext{
12 Termo denominado pela autora para expressar a ideia de que cada um faz ao seu gosto, a sua maneira, como quiser.
}

dimensão organizacional e como dimensão social.

\subsection{Dimensão individual}

Esta dimensão segundo Morin, Tonelli e Pliopas (2007), engloba a satisfação pessoal, autonomia e sobrevivência, aprendizagem e crescimento, bem como a questão da identidade. Como satisfação pessoal, destaca-se a visão de um trabalho que tenha como sentido promover o prazer a quem o exerce, o jovem trabalhador gosta de realizar as atividades da empresa e aprecia o que faz. O sentido de satisfação no trabalho está relacionado à contribuição pessoal do indivíduo para o próprio trabalho. Além disso, o trabalho faz sentido se quem o executa tem a sensação de superar desafios e se seu executor percebe sua contribuição e responsabilidade no trabalho executado.

Quanto à autonomia e sobrevivência, evidencia-se que o dinheiro ganho como fruto do trabalho é associado à perspectiva de autonomia $\mathrm{e}$ independência do trabalhador. Tal autonomia esta presente nos projetos arquitetados pelos jovens para o futuro. Os jovens se percebem trabalhando muitas horas nos dias atuais para progredir na escala hierárquica, passar a receber remunerações maiores e conquistar seus sonhos. Para as autoras, Morin, Tonelli e Pliopas (2007), a autonomia financeira está também relacionada à liberdade de escolha, e a não dependência de outros para tomar decisões.

A aprendizagem e o crescimento mostram que os jovens se preocupam com a estagnação de suas carreiras dentro das empresas. A perspectiva de galgar as escalas hierárquicas traz sentido ao trabalho. Este é o crescimento desejado e esperado dentro do mundo organizacional. Porém, acredita-se que a ascensão organizacional ocorra antes para os mais competentes e para os mais aptos. Assim,

LEONARDI, João C.; GIORDANI, Estela M. O perfil dos jovens colaboradores para o processo de profissionalização e descentralização da empresa. Revista Saber Humano, Recanto Maestro, n. 3, p. 3567, 2013. 
“(...) trabalho com sentido passa a ser aquele que proporciona a aquisição de habilidades e conhecimentos, que permite o aprimoramento de competências do indivíduo" (MORIN, TONELLI e PLIOPAS, 2007, p. 52). A busca por maiores especializações revela uma ambição dos jovens em assumir responsabilidades adicionais às atividades de seus empregos atuais, bem como a procura de um reconhecimento e valorização maior no ambiente de trabalho.

A questão da identidade revela que mesmo com as mudanças frequentes no mercado de trabalho, os jovens encontram nas empresas fontes de orgulho $\mathrm{e}$ identificação com o trabalho. Segundo Morin, Tonelli e Pliopas (2007), “(...) a organização contribui significativamente para a identidade das pessoas: trata-se de um exemplo típico da quase totalidade das pessoas que se apresentam tendo a empresa onde trabalham como complemento de seu nome" (p. 52). Com isso, evidencia-se que a identidade dos jovens trabalhadores em grande medida é formada dentro do ambiente de trabalho, a partir da convivência com colegas e realização de atividades profissionais.

\subsection{Dimensão organizacional}

Nesta dimensão concentram-se duas características: a utilidade e o estabelecimento de relações no ambiente de trabalho. Conforme Morin, Tonelli e Pliopas (2007), muitos jovens veem o sentido do seu trabalho associado à sua utilidade. $O$ trabalho tem sentido se o produto do trabalho servir a algum propósito. Para as autoras:

A percepção da utilidade inclui vários temas: desde a produção de medicamentos e de pesquisas em laboratórios, até o relatório que é elaborado por um dos funcionários e é usado para esclarecer dúvidas em uma reunião. Narrar que um sistema desenvolvido no antigo emprego ainda é utilizado é exemplo de trabalho que faz sentido (p.53).

Além da utilidade é preciso salientar que a percepção do todo, desde o início do processo de produção até o seu fim, também é um fator que faz o trabalho ter significado na vida do jovem, pois este se sente parte do processo e o faz ter reconhecimento $\mathrm{e}$ valor dentro da empresa. Dessa forma, o sentido do trabalho é dado pelo reconhecimento de alguém, que muitas vezes distingue o trabalho do jovem como útil. Segundo Morin, Tonelli e Pliopas (2007), o trabalho se configura numa fonte importante de relacionamentos entre pessoas. É através da convivência no ambiente de trabalho, que os trabalhadores trocam informações, conhecimentos e estabelecem relações com os colegas de profissão.

\subsection{Dimensão Social}

A dimensão social engloba duas características do trabalho na vida dos jovens: a inserção na sociedade e a contribuição para a sociedade. Morin, Tonelli e Pliopas (2007) destacam que para muitos trabalhadores, essencialmente para os jovens, o trabalho representa uma porta de entrada para a sociedade, isto é, o trabalho se configura num meio que possibilita as pessoas a pertencerem ao conjunto social. As autoras ainda citam que: "A formação profissional, o trabalho exercido, a empresa onde o trabalho é exercido e a própria remuneração são papéis que permitem ao homem interagir com diferentes grupos sociais" (p. 54). Mais do que isso, o trabalho para muitos jovens só tem significado quando tem algum valor para a sociedade, o que logo remete à utilidade do trabalho.

Erro! Fonte de referência não encontrada. Analisando essas três dimensões, percebese que o trabalho muitas vezes ocupa um lugar central na vida das pessoas, sendo

LEONARDI, João C.; GIORDANI, Estela M. O perfil dos jovens colaboradores para o processo de profissionalização e descentralização da empresa. Revista Saber Humano, Recanto Maestro, n. 3, p. 3567, 2013. 
indiscutivelmente a principal fonte de sobrevivência. Porém, o trabalho segundo Hackman e Oldham (1976), deve ultrapassar esta concepção. Para os autores, o trabalho deve apresentar variedades e ser desafiador. Morin (2002) evidencia que o trabalho na vida dos jovens deve permitir a utilização do talento e do potencial, possibilitando prazer e satisfação na realização das tarefas, isto é, possibilitando um gosto especial no exercício da própria atividade em si mesma.

Para Morin (2002), o trabalho possui significado quando a contribuição dos trabalhadores é única e criativa. $\mathrm{O}$ trabalho com sentido permite o desenvolvimento da capacidade de autonomia (possibilidade de fazer escolhas e se responsabilizar por elas) e decisão. A autora salienta também que o trabalho proporciona uma aprendizagem contínua, levando os trabalhadores a ganhos maiores no futuro, principalmente para os jovens. Além disso, o processo de trabalho e seus resultados ajudam os jovens a formar a sua identidade.

Conforme Meneghetti (2009), de um cenário no qual o trabalhador era, sobretudo, um executor, guiado por processos e regras muito claras, das quais raramente se desviava, está se deslocando para um cenário no qual o trabalhador tem cada vez mais responsabilidades $\mathrm{e}$ encargos, não trabalha mais com base em horas, mas no alcance de determinados objetivos frequentemente ligados, de algum modo, à sua remuneração. Inclusive o ambiente de trabalho mudou, o trabalhador está cada vez mais móvel, ficando muito tempo fora da empresa e fora dos clássicos horários de trabalho. Estão adquirindo um elevado nível de autonomia e as relações são mais de caráter funcional do que hierárquico.

Para Pregadier e Barbieri (2011), o trabalho faz parte da formação do ser humano e, através dele o indivíduo pode resgatar o sentido da vida. Seguindo este mesmo pensamento, Morin (2002), salienta que para um trabalho ter sentido, ele deve ser realizado de forma eficiente e levar a um resultado, ou seja, os objetivos devem ser claros e os resultados devem ter valor aos olhos de quem o realiza; deve permitir a realização de suas competências. É relevante que o trabalhador tenha a oportunidade de testar suas capacidades, com o objetivo de estimular suas necessidades de crescimento pessoal e seu senso de responsabilidade.

Conforme Pellegrini, Petry e Schutel (2011), o trabalho é uma ordem natural da existência, recebendo desta ordem as leis que o regem, é o único caminho para se alcançar a virtude. $\mathrm{O}$ trabalho envolve a habilidade pessoal e o que dela deriva. O trabalho, conforme Pellegrini, Petry e Schutel (2011) faz parte do ser humano, e por meio dele, o homem pode resgatar o sentido da vida. "É pelo trabalho que o homem, como ser social, passa da condição de sua origem natural baseada nos instintos, para uma produção e reprodução como gênero humano" (p. 11). Neste sentido, o homem faz do trabalho a realização de uma finalidade. É por meio do trabalho que o homem deixa de se adaptar ao ambiente e faz a mediação entre a esfera das necessidades e sua realização. Assim, o trabalho é o mediador entre as necessidades e sua realização.

A atividade de trabalho como argumenta Pregadier e Barbieri (2011), representa para o jovem um desafio, pois exige que este assuma uma postura de autonomia e responsabilidade, arcando com as consequências das suas escolhas. Segundo as autoras: Essa postura de autonomia e
responsabilidade do jovem torna-se cada
vez mais premente no contexto do
trabalho, e isto se deve ao atual e
dinâmico mercado competitivo, que exige
das empresas um alto nível de qualidade e
qualificação de seus colaboradores, não
sendo mais possível esperar que as

LEONARDI, João C.; GIORDANI, Estela M. O perfil dos jovens colaboradores para o processo de profissionalização e descentralização da empresa. Revista Saber Humano, Recanto Maestro, n. 3, p. 3567, 2013. 
pessoas recém contratada se tornem suficientemente experientes até exercerem plenamente suas atividades, além de requerer cada vez mais rapidez para estas atingirem um bom nível de autonomia (p. 107).

Viver em sociedade implica interação com outras pessoas, por esse motivo o momento de tomada de decisão é importante, pois um indivíduo, quando escolhe, afeta a sua vida e a de outros. Por isso, para o jovem, ter a consciência da responsabilidade de suas escolhas pode ser decisivo, principalmente no que diz respeito à atuação do seu próprio potencial e mais do que isso, pode refletir no seu desenvolvimento profissional e no significado que o trabalho terá em sua vida.

Nesta perspectiva, como uma possível conclusão pode-se afirmar que, apesar de fortemente atravessados pelas significações sobre o trabalho produzido em um contexto capitalista, os jovens trabalhadores vivenciam novos sentidos em suas vidas. Apresentam diversos significados ao trabalho, desde a remuneração até a possibilidade de se aperfeiçoar dentro da empresa e estabelecer vínculos e relações de afetividade no ambiente de trabalho. Percebe-se então, que o trabalho possui um valor, tanto de uso como possibilidade humana de interagir diretamente com a natureza e dela extrair seu produto, e num movimento constante, promover sua própria transformação e também do meio. O lugar do trabalho em suas vidas, apesar dessa dialética, é uma oportunidade para ressignificações, pois seus desejos expressam uma busca de ser alguém e de ser feliz a partir do seu trabalho, o que corrobora com a compreensão do lugar de centralidade ocupado por essa categoria na vida dos jovens.

\section{A formação Life Long Learning para jovens na empresa}

A atualização continuada é um meio de propiciar ao ser humano uma permanente adaptação às constantes transformações do contexto da sociedade complexa em que o jovem se insere. As mudanças ao longo do tempo são inevitáveis e o modelo de formação capaz de abarcar continuidades e transformações é ainda muito discutido nos cenários das reformas da educação superior no mundo, mas também no contexto das organizações que percebem a necessidade desta nova perspectiva na relação produtiva.

Desenvolvida há mais de quarenta anos, a ciência ontopsicológica possui como uma das áreas de atuação a pedagogia para o jovem. Ela considera o jovem aquele que "tem íntegro o potencial de poder dar evolução biológica, funcional, estética, carismática e, portanto, de liderança como 'top líder"' integral" (MENEGHETTI, 2005, p. 343).

A aprendizagem ao longo da vida, desenvolvida por meio dessa visão implica em considerar como critério o Em $\mathrm{Si}$ ôntico individuado em contexto histórico, e segundo a normotipia deste genoma ôntico são coordenados os meios para atingir os fins. $O$ autopor-se na história por meio de escolhas assertivas implica uma constante capacidade de transparência e reversibilidade entre o que a mente representa e o que o real apresenta. Eis então a necessidade da revisão crítica da consciência e da educação continua no sentido de possibilitar a aprendizagem do critério que promove a identidade e o utilitarismo funcional ao sujeito e, portanto, a capacidade de fazer escolhas que realizem o seu potencial integral (MENEGHETTI, 2005).

Pensar pedagogia no interno dos processos produtivos do trabalho implica em muito mais do que compreender a natureza do trabalho e a organização de

LEONARDI, João C.; GIORDANI, Estela M. O perfil dos jovens colaboradores para o processo de profissionalização e descentralização da empresa. Revista Saber Humano, Recanto Maestro, n. 3, p. 3567, 2013. 
competências essenciais para desenvolver nos colaboradores. $\mathrm{Na}$ empresa, a condução do colaborador seria com o escopo para "saber e fazer a si mesmo: fazer uma pedagogia de si mesmo como pessoas líderes no mundo: educar o Eu lógico histórico com capacidade de condutas vencedoras" (grifo do autor) (idem, p. 21).

Meneghetti (2003) expõe que os estilos de vida são o viver, o ofício de viver e a arte de viver. Apesar de os estilos de vida referir-se à pessoa, seja um jovem ou o líder, é possível transpor esses estilos para as empresas. Na verdade, para a empresa evoluir ela depende da evolução do líder e dos colaboradores, assim, o estilo de vida do líder e seus colaboradores pode levar a empresa à evolução. É neste sentido que se pode transpor o conceito de estilo de vida também para a organização. Ou seja, a empresa assim como o líder e o jovem colaborador podem possuir um estilo de vida propulsor de criatividade contínua.

Para o autor, a escolha é fundamental visto que "não é a origem da alma ou a superioridade do berço que dão a realização [...]. O gênio é aquele que sabe dar continuidade progressiva a si mesmo e à história (MENEGHETTI, 2009, p. 07).

A empresa que definir, por meio do líder existir para viver é caracterizada por um adequado funcionamento, segue o ritmo do mercado, cumpre com as suas demandas, interage com o contexto, enfim, possui os meios ordenados ao seu fim. Também o indivíduo que escolhe o viver ingressa na normotipia da vida humana, vive segundo as leis biológicas da natureza humana e, portanto, pode-se dizer que suas necessidades básicas são supridas. Pensando no universo do trabalho e transpondo o viver no contexto da empresa, para o jovem trata-se daquele que possui uma qualificação profissional e desempenha adequadamente as suas funções. Funciona de modo que faz com que a organização tenha realizado as necessidades básicas.

$\mathrm{O}$ ofício de viver remete à compreensão de exercer a vida com um estilo destacado dos demais, requer uma preparação superior e também uma atitude permanente de ora e laborat, ou seja, de aprimoramento, primor e estado de revisão de sua atividade psíquica. Neste estilo o que os diferencia dos que vivem é que:

Enquanto o primeiro nível percorre os modelos de vida como absolutos totalitários, o segundo usa $\mathrm{o}$ ou os modelos simplesmente como meios ao próprio fim e os observa na medida em que merecem credibilidade por parte dos outros. Os primeiros são aqueles que crêem, os segundos usam aquilo que o próximo crê (MENEGHETTI, 2003, p. 14).

Esta é uma visão de uma organização orgânica, isto é, não apenas tem um funcionamento adequado, mas este se revela diverso e destacado em relação aos demais, assim também o líder e o colaborador. Os indivíduos ou as organizações compreendem a sua finalidade e assim responsabilizam-se por atuar em um patamar superior de existência.

O estilo de vida como arte é aquele que se atua a

Capacidade de agir sobre a vida, através de modelos de ação que determinam uma novidade de ser na existência. Ao invés de repetir o ciclo objetual da existência, o indivíduo inventa comportamentos de função tão destacada, que lhe consentem objetivar a existência como fundo natural de jogo da própria personalidade. (MENEGHETTI, 2003, p. 15).

Esse estilo depende de um operador autêntico que seja capaz de gerenciar a materialidade da vida em função instrumental da sua volição. A vida é exercida como técnica ao belo, justo e bom uma vez que exercendo arte, ou seja, "aquilo que dá lugar à forma da

LEONARDI, João C.; GIORDANI, Estela M. O perfil dos jovens colaboradores para o processo de profissionalização e descentralização da empresa. Revista Saber Humano, Recanto Maestro, n. 3, p. 3567, 2013. 
força" (idem).

Conforme Meneghetti "é

necessário criar um novo 'humanismo do trabalho, que exalte a liberdade do homem, a sua criatividade, e os seus dotes intelectuais e morais" (MENEGHETTI, 2007, p. 11). A técnica ontopsicológica aplicada no interior das relações de trabalho na empresa, visa desenvolver o potencial humano a partir do seu critério de natureza, por meio do qual as suas escolhas refletem a reversibilidade entre a representação e o real e, com isso, tem o critério para tornar a sua intuição exata (MENEGHETTI, 2007). Trata-se de desenvolver o potencial humano, sua inteligência que é a movente de toda e qualquer realidade no contexto operativo.

Com essa visão a empresa e o empregador concretamente oferecem ao colaborador jovem a possibilidade real de crescimento por meio da formação life long learning, assim, o jovem, conforme Meneghetti (2007, p. 11) necessita de "técnica específica no campo de atuação que pode ser aprendida em uma empresa; técnica de personalidade, entendida como o savoir-faire, que é a inteligência centrada na ação específica de serviço à empresa, e onde a pessoa é fundamental e determinante". Nesta relação, tanto a empresa quanto o jovem tornam-se protagonistas responsáveis em fazer bem o próprio trabalho. A empresa neste sentido, torna-se permanente espaço de provocação e crescimento para o colaborador. O colaborador aprendendo o saber servir, compreende que fazendo bem o seu trabalho, este retorna em desenvolvimento de seu potencial empreendedor e, com isso, o ganho se realiza de maneira integral para o colaborador e também para a empresa, é a lógica do ganho mútuo.

\section{Metodologia}

A pesquisa foi desenvolvida a partir das abordagens quali-quantitativas em ciências sociais aplicadas e, se configura como um estudo de caso pois estuda os jovens colaboradores de uma empresa tendo em vista que busca conhecer a realidade destes colaboradores para alinhar as mudanças identificadas como necessárias a partir do investimento em formação continuada da equipe que está na empresa. Conforme Hair et al (2007), esse é um objetivo das pesquisas no campo da administração, ou seja, auxiliar na tomada de decisões de questões estratégicas e táticas: "a pesquisa em administração objetiva levar a melhores decisões" (p. 33). Assim, considera-se fundamental focar as problemáticas em contextos circunstanciados, visto que, o estudo dos fatos daquela realidade pode ser compreendido em maior profundidade (CAMPOMAR, 1991).

Deste modo, adotou-se o estudo de caso dos colaboradores jovens da empresa a fim de realizar a exploração de dados a respeito de suas características, gostos, preferências e principalmente identificar os seus estilos de vida e perceber a relação destes com o trabalho na empresa. Apesar dos colaboradores serem parte da empresa, sem a exploração mais profunda destas informações não se consegue conhecer aspectos importantes sobre suas vidas e se tais aspectos produzem interferências significativas no contexto da organização, visto que, ela está se profissionalizando e para isso é necessário investir no capital humano que dispõe. Este estudo de caso foi realizado com uma amostra selecionada por conveniência abrangendo os jovens que se destacam no exercício de suas funções e que apresentam características e atitudes que demonstram o seu valor e potencial de desenvolvimento. A participação ou não na pesquisa foi voluntária conforme as disposições éticas e legais para a realização de pesquisa científica em seres humanos.

LEONARDI, João C.; GIORDANI, Estela M. O perfil dos jovens colaboradores para o processo de profissionalização e descentralização da empresa. Revista Saber Humano, Recanto Maestro, n. 3, p. 3567, 2013. 
A empresa em que a pesquisa foi realizada tem 22 anos de atuação no segmento da construção civil, sendo especializada em construções préfabricadas de concreto. Sua atividade é bastante complexa e compreende:

1) Comercialização técnica: orientação aos clientes focada na busca da otimização da solução estrutural e principais serviços complementares para a edificação dos empreendimentos. Em alguns casos, significa auxilio ao cliente para conceber a obra.

2) Projetos e engenharia: elaboração dos projetos, dimensionamentos, cálculo estrutural e desenvolvimento de soluções customizadas necessárias para os empreendimentos.

3) Industrialização: produção dos elementos de concreto pré-fabricados, armados e pretendidos, que irão compor as estruturas, em uma unidade fabril dentro de rígidos controles de qualidade.

4) Logística: como se trata de peças de concreto de grandes dimensões e pesadas, o planejamento e operacionalização de logística são fundamentais para que se consiga produtividade, tanto na fábrica como nas obras.

5) Serviços: Compreende a gestão dos contratos e execução dos serviços que serão realizados nos canteiros de obras que normalmente incluem: fundações, montagem da estrutura pré-fabricada, cobertura, fechamentos industrializados $\mathrm{e}$ alguns complementos.

A empresa executa apenas uma etapa da construção, mas é a primeira e mais importante da obra, pois é necessário o planejamento de toda à obra e a definição das interfaces com os outros serviços que serão executados posteriormente. Os cronogramas de execução são sempre bem apertados, contendo serviços de natureza distintas e interdependentes entre si que requerem recursos e equipes específicas para sua realização. Como são obras rápidas, tem sempre um grande número de contratos ativos simultaneamente.

Em dezembro de 2009, a empresa que estava sediada na capital paulista, transferiu-se para o interior do estado em função da necessidade de expansão da sua usina de produção de elementos préfabricados e problemas decorrentes da urbanização na sua vizinhança. Aproveitando a implantação da nova fábrica, foi implementada uma significativa alteração nas principais linhas de produção e soluções estruturais pré-fabricadas. Também foram desenvolvidos dois novos produtos que complementam os sistemas construtivos industrializados oferecidos ao mercado. Por consequência, também mudou o perfil de empreendimentos que se executa e o foco nos clientes que precisam ser conquistados.

Porém, a mudança acarretou uma grande renovação no quadro de colaboradores, especialmente entre os jovens que tinham vínculos familiares, social ou de estudo na capital. Por mais que tenha sido planejado e mesmo com a adoção de várias medidas para minimizar o impacto desta perda da inteligência e identidade da empresa, o resultado foi mais crítico do que se previa. Portanto, não se trata de uma empresa consolidada, mas que está passando por uma fase de grandes mudanças e assim tentando se renovar. A consolidação significaria entrar em uma nova fase de tranqüilidade e colheita. Renascendo, vai reaprender a fazer melhor as mesmas coisas que fazia antes. Portanto, deve sair de uma zona de "pseudo-conforto" para mergulhar em uma fase de empenho e dedicação abrindo um novo horizonte de perspectivas para o futuro da organização.

LEONARDI, João C.; GIORDANI, Estela M. O perfil dos jovens colaboradores para o processo de profissionalização e descentralização da empresa. Revista Saber Humano, Recanto Maestro, n. 3, p. 3567, 2013. 
A missão da empresa é "desenvolver e executar soluções construtivas industrializadas, com o compromisso de otimizar os empreendimentos de nossos clientes, facilitando e agilizando $\mathrm{o}$ ato de construir”. E, seus valores são:

resultado: otimizar o desempenho da empresa para maximizar os resultados; cliente: saber servir, servir com excelência (agilidade, comprometimento e transparência); humano: trabalho como espaço de realização e crescimento; confiabilidade: priorizar a segurança e corresponder a todas as expectativas criadas; empreendedorismo: antecipar-se às necessidades, realizando-as com dinamismo e criatividade, em um ambiente de auto-gestão; sustentabilidade: prover as condições necessárias para a segurança $\mathrm{e}$ preservação da vida e do meio ambiente, agora e no futuro (Planejamento Estratégico da Empresa pesquisada).

A empresa vem obtendo um crescimento aproximado de $35 \%$ ao ano, nos últimos cinco anos $\mathrm{e}$, as novas instalações permitem a continuidade desse crescimento. A empresa tem como visão consolidar-se como a melhor empresa em soluções construtivas industrializadas do país.

A coleta de dados foi realizada a partir da aplicação de um questionário estruturado, com questões abertas e fechadas composto por quatro partes: 1) identificação; 2) a relação jovem e a família; 3) a relação jovem antes da empresa; 4) a relação do jovem atualmente na empresa. Os questionários foram auto-aplicáveis, ou seja, os próprios indivíduos responderam os questionários sem a sua identificação. Foram respondidos por 32 jovens com o seguinte perfil em relação ao sexo, estado civil, se possui filhos e a quantidade de filhos.

Dos jovens pesquisados $62 \%$ são do gênero masculino e $38 \%$ feminino. E, em relação à função ocupada na empresa pode-se observar a Figura 1.

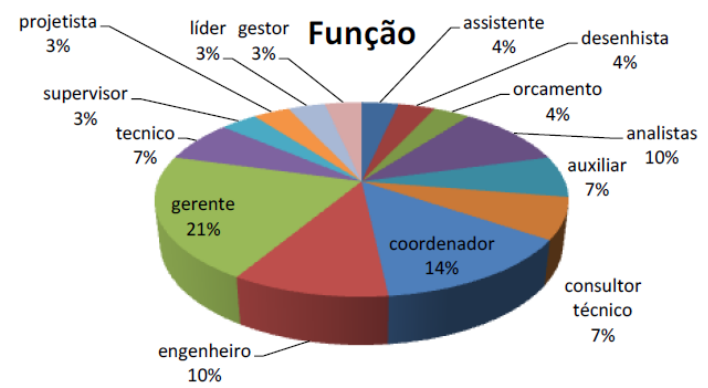

Figura 1: Função

Observa-se que a distribuição da amostra em relação à ocupação é bem dispersa, considerando que a pesquisa foi realizada com jovens dos quais alguns já ocupam cargos de chefia ou que possuem algum destaque de liderança na empresa.

Em relação ao Estado em que nasceu, observa-se na figura 2 a predominância do Estado de São Paulo, onde se encontra a empresa, com $87 \%$ da amostra.

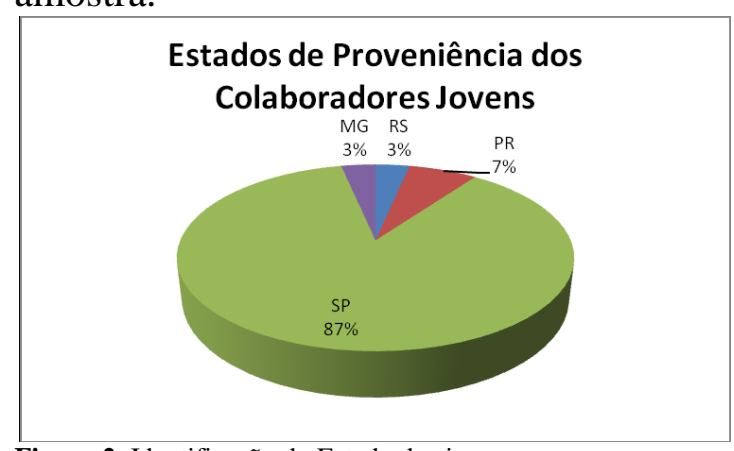

Figura 2: Identificação do Estado dos jovens

Em relação ao estado civil dos jovens da empresa, pode-se evidenciar que $59 \%$ são solteiros, $31 \%$ são casados e, $10 \%$ possuem outra situação, conforme os dados da figura 3 .

\section{ESTADO CIVIL}

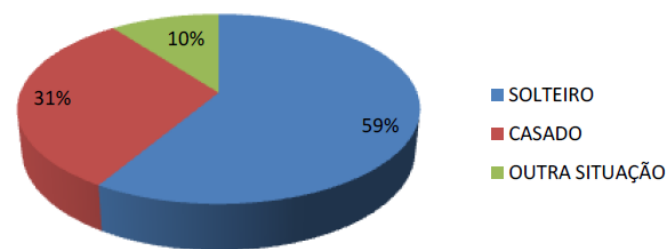

Figura 3: Estado civil dos jovens

Dos jovens que possuem filhos, pode-se observar que apenas $21 \%$ deles

LEONARDI, João C.; GIORDANI, Estela M. O perfil dos jovens colaboradores para o processo de profissionalização e descentralização da empresa. Revista Saber Humano, Recanto Maestro, n. 3, p. 3567, 2013. 
possuem filhos, enquanto $79 \%$ não possuem (Figura 4).

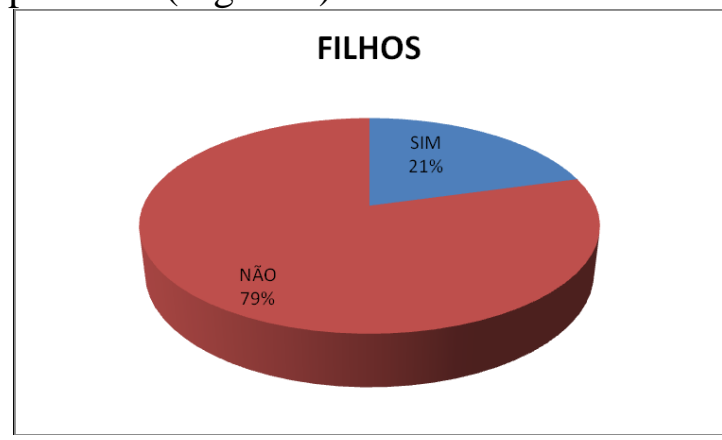

Figura 4: Jovens pesquisados possuem filhos

A Figura 5 indica a quantidade de filhos que possuem, sendo que, $13 \%$ afirma ter apenas um filho, $6 \%$ indica ter mais de um filho e $81 \%$ indica não ter filhos.

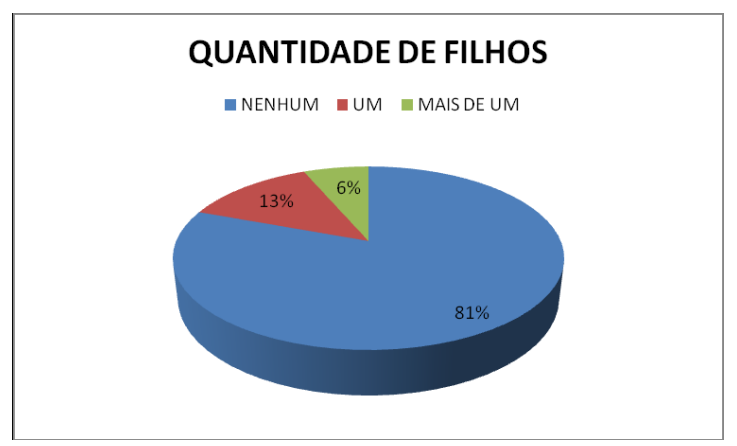

Figura 5: Quantidade de filhos dos jovens pesquisados

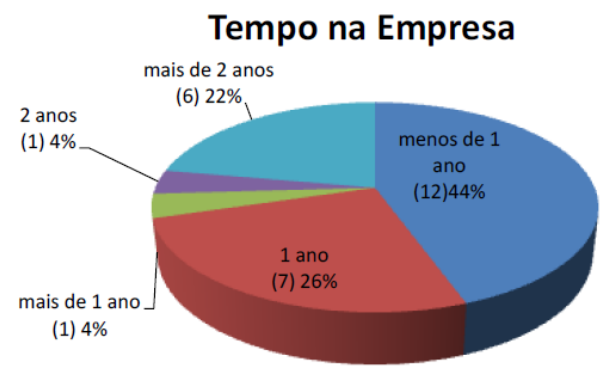

Figura 6: Tempo na empresa

Pode-se observar que a maioria dos jovens possui até dois anos de empresa, indicando uma equipe ainda em formação.

\section{Motivação de Trabalhar na Empresa}

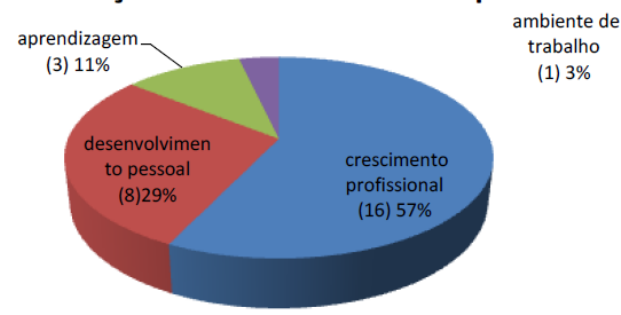

Figura 7: Motivação de trabalhar na empresa

Observa-se que as motivações maiores são o crescimento profissional (57\%), seguido do desenvolvimento pessoal $(29 \%)$ e a aprendizagem $(29 \%)$. O ambiente de trabalho também foi apontado por $3 \%$ dos pesquisados. Notase que o perfil dos jovens está focado no desenvolvimento, o que revela um potencial para a implantação da formação continuada para a equipe.

Para a análise quantitativa dos dados optou-se pela aplicação da análise estatística multivariada também denominada Análise Multivariada (multivariate analysis), pois a mesma permite a análise simultânea considerando o conjunto total das variáveis originais. Para esta pesquisa foram aplicadas as técnicas de análise fatorial e análise de componentes principais.

Conforme Pereira (2001), a Análise fatorial (Factor analysis) é utilizada pelo pesquisador para avaliar no conjunto de suas variáveis, aquelas que possuem maior significado de explicação para a sua problemática de pesquisa ou conjunto de variáveis mensuradas. A análise fatorial tem como objetivo principal explicar a correlação ou covariância, entre um conjunto de variáveis, em termos de um número limitado de variáveis nãoobserváveis. Essas variáveis nãoobserváveis ou fatores são calculados pela combinação linear das variáveis originais.

Análise de componentes principais (Principal component analysis) objetiva obter um pequeno número de combinações lineares (componentes

LEONARDI, João C.; GIORDANI, Estela M. O perfil dos jovens colaboradores para o processo de profissionalização e descentralização da empresa. Revista Saber Humano, Recanto Maestro, n. 3, p. 3567, 2013. 
principais) de um conjunto de variáveis, que retenham o máximo possível da informação contida nas variáveis originais. Freqüentemente, um pequeno número de componentes pode ser usado, em lugar das variáveis originais, nas análises de regressões, análises de agrupamentos e outras. Os Componentes são extraídos na ordem do mais explicativo para o menos explicativo. Teoricamente o número de Componentes é sempre igual ao número de variáveis. Entretanto, alguns poucos Componentes são responsáveis por grande parte da explicação total.

Para a crítica do questionário aplicado para o grupo, será realizada a análise através do teste de Friedman, onde são comparados os valores calculados com valores da tabela de distribuição quiquadrado, de acordo com os graus de liberdade. $O$ teste de Friedman é empregado quando existem mais de duas condições de emparelhamento, onde cada variável é classificada numa escala de nível ao menos ordinal.

Determinado o procedimento de análise, expõe-se a seguir as variáveis em estudo:

- H0: não existe diferença significativa entre as respostas, ao nível de 5\% de significância em relação as variáveis de identificação da amostra, a relação jovem e a família, a relação jovem e empresa;

- H1: existe diferença significativa entre as respostas, ao nível de 5\% de significância em relação as variáveis de identificação da amostra, a relação jovem e a família, a relação jovem e empresa.

Compara-se o valor obtido pelo teste com o valor de qui-quadrado tabelado. Quando o valor obtido pelo teste for maior do que qui-quadrado tabelado, rejeita-se H0. Quando o valor obtido pelo teste for menor do que qui-quadrado tabelado, aceita-se H0. O valor de " $p$ ", obtido através do teste, demonstra a significância obtida quando comparado com o nível de significância adotado. Definiu-se para todos os testes um nível de significância de 5\%. E, para efetuar as análises foram utilizadas a planilha eletrônica Excel e o software "Statistica 7.0".

Para as questões que exigiram uma resposta descritiva dos pesquisados, procedeu-se a análise qualitativa por meio da aglutinação temática das respostas, conforme a técnica de analise de conteúdo de Bardin (1977). A autora orienta que, depois de lidas as respostas, estas sejam organizadas em temas e depois categorizadas a fim de caracterizar e compor a compreensão daquela variável de forma mais completa possível.

\section{Os jovens e o trabalho na empresa}

Desenvolve-se, a seguir, a análise estatística dos dados coletados por meio dos questionários aplicados aos jovens da empresa investigada. $\mathrm{Na}$ primeira parte analisam-se todas as questões referentes a II, III e IV $^{13}$ partes do questionário relativas a: a relação jovem e a família, a relação jovem e empresa antes (parte III) e depois (parte IV). Estas variáveis foram analisadas por meio de técnicas estatísticas multivariadas dos componentes principais e da análise fatorial, fazendo a verificação do teste das variáveis por meio do Teste de Friedman.

Após esta análise das três partes do questionário, extraiu-se algumas variáveis isoladas para estabelecer a correlação de seu comportamento em relação a percepção dos jovens antes e depois de ingressarem na empresa.

\footnotetext{
${ }^{13}$ A primeira parte relativa à identificação da amostra já foi tratada e apresentada na metodologia.
}

LEONARDI, João C.; GIORDANI, Estela M. O perfil dos jovens colaboradores para o processo de profissionalização e descentralização da empresa. Revista Saber Humano, Recanto Maestro, n. 3, p. 3567, 2013. 
Como na análise fatorial são necessários valores maiores que um e devem conjuntamente expressar um poder de explicação superior a 70\%, observou-se que dos dados coletados, somente os cinco primeiros autovalores (eigenvalues) devem ser considerados, pois apresentam um poder de explicação de 73,22020\%, conforme observado na figura seguinte.

\begin{tabular}{|c|c|c|c|c|}
\hline \multirow[b]{2}{*}{ Value } & \multicolumn{4}{|c|}{$\begin{array}{l}\text { Eigenvalues } \\
\text { Extraction: Principal components }\end{array}$} \\
\hline & \begin{tabular}{|l} 
Eigenvalue \\
\end{tabular} & $\begin{array}{c}\% \text { Total } \\
\text { variance }\end{array}$ & $\begin{array}{l}\text { Cumulative } \\
\text { Eigenvalue }\end{array}$ & $\begin{array}{c}\text { Cumulative } \\
\%\end{array}$ \\
\hline 1 & 4.576345 & 25.42414 & 4.57634 & 25.42414 \\
\hline 2 & 3.550766 & 19.72648 & 8.12711 & 45.15062 \\
\hline 3 & 2.087846 & 11.59915 & 10.21496 & 56.74976 \\
\hline 4 & 1.631648 & 9.06471 & 11.84661 & 65.81448 \\
\hline 5 & 1.333030 & 7.40572 & 13.17964 & 73.22020 \\
\hline 6 & 1.210366 & 6.72426 & 14.39000 & 79.94446 \\
\hline 7 & 1.136971 & 6.31651 & 15.52697 & 86.26096 \\
\hline 8 & 1.036542 & 5.75856 & 16.56351 & 92.01953 \\
\hline
\end{tabular}

Os autovalores representam novas variáveis resultantes da combinação das variáveis originais, resultantes das componentes principais. Cada autovalor é responsável por um percentual de explicação das variáveis analisadas, segundo uma ordem decrescente de explicação, conforme a figura anterior. Com isso pode-se reduzir o número de variáveis, sendo, portanto, eleitas as mais significativas conforme o cálculo das cargas fatoriais resultantes da análise de todas as variáveis contemporaneamente. A seguir, portanto, expõe-se a análise de todas as variáveis, sendo que as mais significativas são aquelas em que as suas cargas fatoriais atingiram o poder de explicação de mais do que 0,7 ou $70 \%$ de explicação em relação às demais.

Perceber-se que para o Fator 1 (variáveis que mais se destacaram pelo cálculo das cargas fatoriais estarem com mais de 70\%) está a variável formação das mães. Compreende-se que esta variável destacou-se, pois das 32 mães dos jovens pesquisados 15 delas possuem o ensino médio completo e 8 delas possuem o ensino superior completo e, as demais com o ensino fundamental completo ou incompleto. Algumas delas possuem inclusive especialização profissional. Para o Fator 2 a variável destacava-se no ensino médio ou universitário acima da média da turma (16 dos 32 responderam afirmativamente essa opção).

$\mathrm{Na}$ figura a seguir apresenta-se o círculo de correlação unitária em relação aos fatores 1 e 2 , responsáveis pela maior porcentagem de explicação e sendo considerados como os fatores principais. Observa-se a disposição de variáveis em cada um dos quadrantes e, pelo diagrama, pode-se observar as variáveis mais significativas para os fatores 1 e 2 , o que pode ser confirmado através das cargas fatoriais demonstrado na figura.

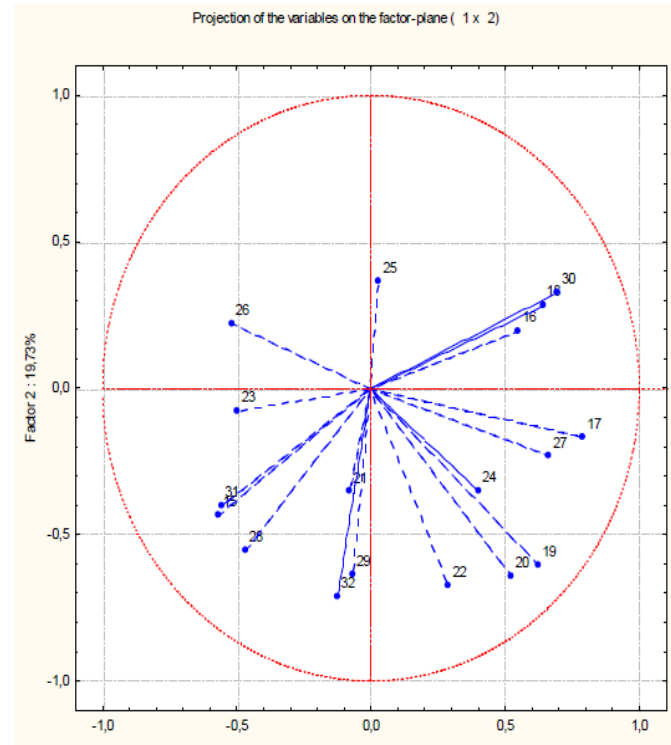

Figura 9: Círculo de correlação unitário para as variáveis analisadas considerando a Parte- II do questionário do grupo analisado

As variáveis mais próximas à extremidade do círculo são consideradas as mais representativas em relação às demais. Observa-se que ocorre uma semelhança entre a disposição no círculo de correlação unitário e os planos principais. Também se observa que as variáveis que se encontram dispostas em quadrantes opostos, indicam uma correlação inversa entre as mesmas. $\mathrm{Na}$ Figura 11 observa-se a distribuição dos

LEONARDI, João C.; GIORDANI, Estela M. O perfil dos jovens colaboradores para o processo de profissionalização e descentralização da empresa. Revista Saber Humano, Recanto Maestro, n. 3, p. 3567, 2013. 
casos nos planos fatoriais.

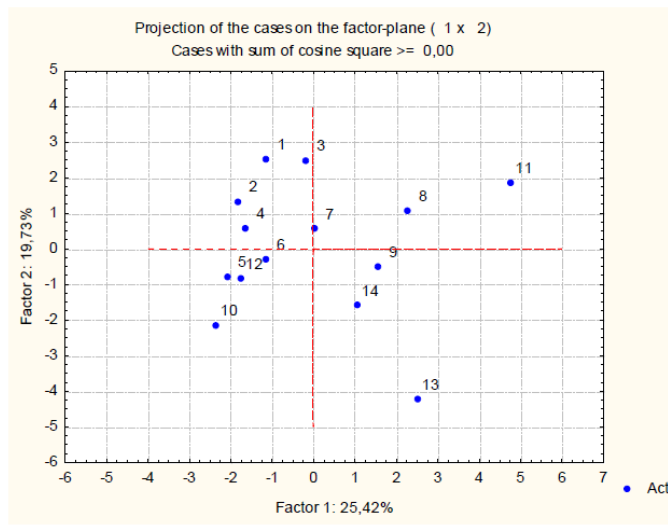

Figura 10: Disposição dos casos nos planos fatoriais conforme as variáveis analisadas da Parte-II do questionário, nos planos principais (fator $1 \mathrm{x}$ fator 2), para o grupo analisado.

A fim de determinar a significância das variáveis analisadas, aplicou-se o teste de Friedman, em que são comparados os valores calculados com valores da tabela de distribuição qui-quadrado, de acordo com os graus de liberdade. Optou-se por selecionar somente as variáveis mais significativas, de acordo com os valores obtidos pelas cargas fatoriais. Na figura seguinte são apresentados os resultados para o teste.

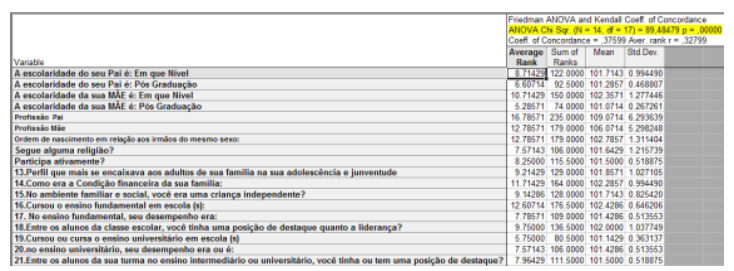

Figura 11: Resultado do teste de Friedman para as variáveis de caracterização para as variáveis analisadas da Parte-III do questionário

Como qui-quadrado calculado é maior $(89,48479)$ do que o valor tabelado $(27,587)$, rejeita-se $\mathrm{HO}$ e aceita-se $\mathrm{H} 1$, ou seja, existe diferença significativa entre as respostas, ao nível de 5\% de significância. $\mathrm{O}$ valor de " $p$ ", obtido através do teste $(0,00000)$, demonstra a significância obtida quando comparado com o nível de significância adotado $(0,05)$. As variáveis mais significativas são observadas na coluna de ordenação (average ranks) na
Figura 9. As variáveis que tem maior valor de ordenação são as mais significativas, ou seja, aquelas que têm um maior poder de explicação.

Pode-se então, em relação a segunda parte do questionário que avaliou a relação jovem e a família, conclui-se que os fatores da formação da mãe e dos jovens estão entre a média e acima da média entre seus colegas no ensino médio e no ensino superior são as variáveis mais significativas e, que, portanto, discriminam o grupo.

Em relação à terceira parte do questionário, que avalia a relação do jovem com o trabalho $\mathrm{e}$ as suas preferências antes de ingressar na empresa atual, pode-se observar, na Figura 13, que fazendo o cálculo dos autovalores, são sete aqueles que possuem o valor e que explicam 74,64186\% das variáveis relativas à terceira parte do questionário, conforme segue:

\begin{tabular}{|c|c|c|c|c|}
\hline \multirow[b]{2}{*}{ Value } & \multicolumn{4}{|c|}{$\begin{array}{l}\text { Eigenvalues } \\
\text { Extraction: Principal components }\end{array}$} \\
\hline & Eigenvalue & $\begin{array}{c}\% \text { Total } \\
\text { variance }\end{array}$ & $\begin{array}{l}\text { Cumulative } \\
\text { Eigenvalue }\end{array}$ & $\begin{array}{c}\text { Cumulative } \\
\%\end{array}$ \\
\hline 1 & 3705 & 20.56526 & 4.31870 & 20.56526 \\
\hline 2 & & 12.87586 & 7.02264 & \\
\hline 3 & 2.384211 & 11.35338 & 9.40685 & 44.79451 \\
\hline 4 & 1.907094 & 9.08140 & 11.31394 & 53.87591 \\
\hline 5 & 1.610584 & 7.66945 & 12.92452 & 61.54535 \\
\hline 6 & 1.457709 & 6.94147 & 14.38223 & 68.48683 \\
\hline 7 & 1.292556 & 6.15503 & 15.67479 & 74.64186 \\
\hline
\end{tabular}

Figura 12: Número de autovalores e \% de explicação para variáveis da Parte-III do questionário do grupo analisado

Tendo calculado os autovalores procedeu-se o cálculo das cargas fatoriais, e observando-se os resultados expostos na Figura 14, para o Fator, 1 duas foram as variáveis que atingiram a porcentagem de significância: as atividades que mais investiam tempo antes de trabalhar na empresa (27.5) foi em internet e assistir TV e o comprometimento e determinação foram as atitudes que mais identificavam em suas vidas antes de trabalhar na empresa (28.4).

LEONARDI, João C.; GIORDANI, Estela M. O perfil dos jovens colaboradores para o processo de profissionalização e descentralização da empresa. Revista Saber Humano, Recanto Maestro, n. 3, p. 3567, 2013. 


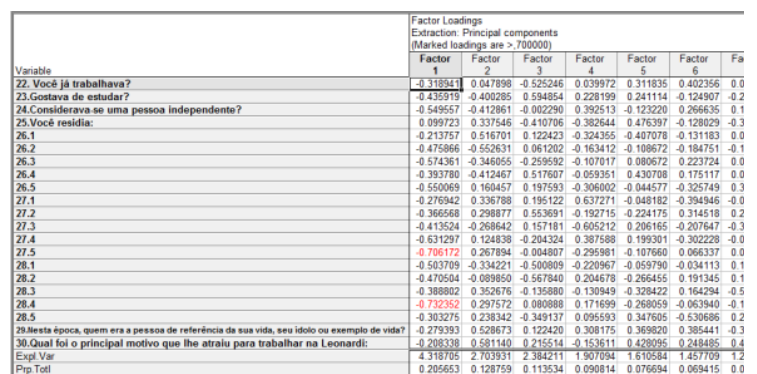

Figura 13: Cargas fatoriais para as variáveis analisadas, considerando variáveis da Parte- III do questionário do grupo analisado

No círculo de correlação unitário pode-se observar nela as distribuições das variáveis em relação aos fatores 1 e 2 , responsáveis pela maior porcentagem de explicação e sendo considerados como os fatores principais. Observa-se a disposição de variáveis em cada um dos quadrantes e, pelo diagrama, aquelas mais significativas são as que estão mais próximas as extremidades do círculo, representando o mesmo resultado das cargas fatoriais demonstrado na Figura 13.

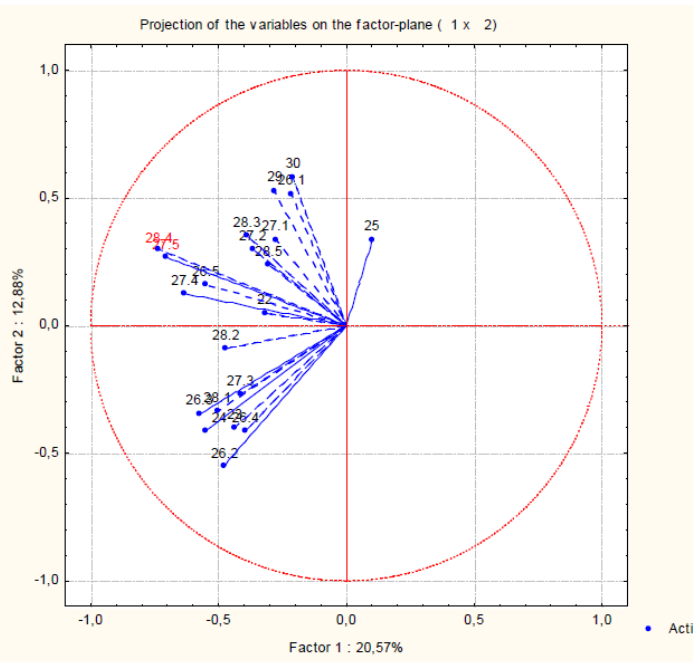

Figura 14: Círculo de correlação unitário para as variáveis analisadas, considerando a Parte- III do questionário do grupo analisado

A seguir, expõe-se a distribuição dos casos nos planos fatoriais (fator $1 \mathrm{X}$ fator 2).

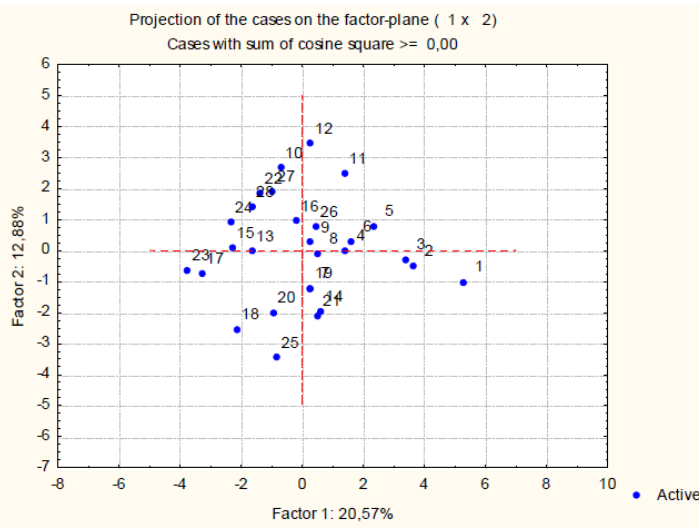

Figura 15: Disposição dos casos nos planos fatoriais conforme as variáveis analisadas da Parte-III do questionário nos planos principais (fator $1 \mathrm{x}$ fator 2 ), para o grupo analisado

Estabelecido o cálculo do quiquadrado que é 223,9020, percebe-se que é maior que o valor tabelado 31,410, conforme a Figura 16.

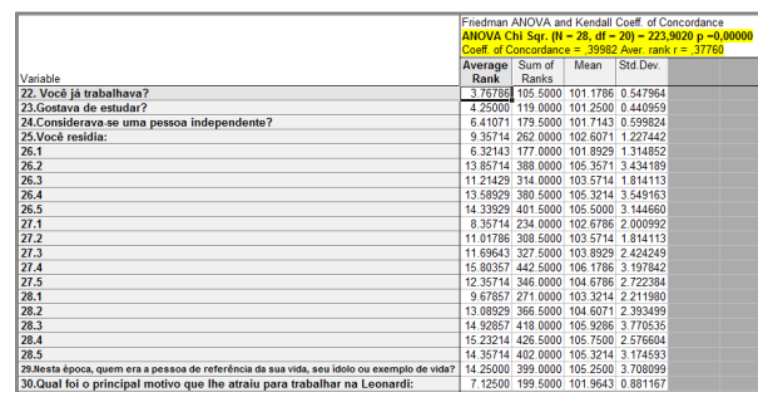

Figura 16: Resultado do teste de Friedman para as variáveis de caracterização analisadas na Parte-III do questionário.

Portanto, aceita-se neste caso a $\mathrm{H} 1$, ou seja, houve significância quando comparado com o nível de significância adotado $(0,05)$ nesta pesquisa, em relação às variáveis analisadas sobre as preferências dos jovens com o trabalho e as suas preferências antes de ingressar na empresa atual.

A seguir elegeu-se algumas variáveis para verificar se existe diferença significativa no perfil dos jovens antes e depois de ingressarem na empresa atual, com o objetivo de determinar se existe uma alteração, de comportamento entre as mesmas.

Em relação às questões que identificavam se houve alteração no gosto pelo estudo antes e depois de ingressar na empresa (questões 23 e 34). Realizando o

LEONARDI, João C.; GIORDANI, Estela M. O perfil dos jovens colaboradores para o processo de profissionalização e descentralização da empresa. Revista Saber Humano, Recanto Maestro, n. 3, p. 3567, 2013. 
cálculo dos autovalores para determinar o grau de significância dessas duas variáveis observou-se o que segue:

\begin{tabular}{|l|l|r|l|c|}
\hline \multicolumn{4}{|l|}{} & \multicolumn{3}{|l}{$\begin{array}{l}\text { Eigenvalues } \\
\text { Extraction: Principal components }\end{array}$} \\
\cline { 2 - 5 } Value & Eigenvalue & $\begin{array}{c}\text { \% Total } \\
\text { variance }\end{array}$ & $\begin{array}{l}\text { Cumulative } \\
\text { Eigenvalue }\end{array}$ & $\begin{array}{c}\text { Cumulative } \\
\%\end{array}$ \\
\hline 1 & 1.623377 & 81.16883 & 1.623377 & 81.16883
\end{tabular}

Figura 17: Número de autovalores, autovalores e \% de explicação para as variáveis analisadas (23 e 34)

Observa-se somente um autovalor explicando $81,16883 \%$, portanto, observase a seguir as cargas fatoriais e a relação entre si.

\begin{tabular}{||l|l|}
\hline \multirow{2}{*}{ Variable } & $\begin{array}{l}\text { Factor Loadings } \\
\text { Extraction: Principal components } \\
\text { (Marked loadings are >,700000) }\end{array}$ \\
\cline { 2 - 3 } & $\begin{array}{c}\text { Factor } \\
1\end{array}$ \\
\hline 23.Gostava de estudar? & 0.900937 \\
\hline 34.Gosta de estudar? & 0.900937 \\
\hline Expl.Var & 1.623377 \\
\hline Prp.Totl & 0.811688 \\
\hline
\end{tabular}

Figura 18: Cargas fatoriais para as variáveis analisadas (23 e 34)

Deste cálculo expresso na Figura 17 , pode-se perceber que ambas as cargas fatoriais são significativas. E, aplicando o teste dos sinais, verifica-se que não existe alteração significativa entre os resultados obtidos entre antes e depois.

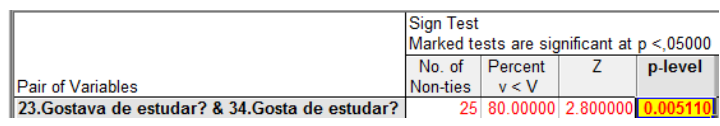

Figura 19: Resultado do teste dos sinais para as variáveis 23 e 34

Como 0,005110 é menor do que o nível de significância adotado $(0,05)$, aceita-se a hipótese alternativa $\mathrm{H} 1$. Ou seja, houve alteração: os indivíduos passaram a gostar mais de estudar. Entende-se que este resultado é positivo, pois os jovens não só mantiveram os interesses de estudo e formação que possuíam antes, mas aumentaram. Esse dado é importante, pois como a pretensão é no investimento da formação continuada dos colaboradores é fundamental que o gosto pelo estudo esteja presente.

No que se refere ao estilo de vida privada do jovem em relação a com quem residia antes e agora (questões 25 e 33), com os cálculos dos autovalores pode-se determinar o que é demonstrado na Figura a seguir:

\begin{tabular}{||l|l|l|l|c|}
\hline \multicolumn{4}{|l|}{} & \multicolumn{3}{|l}{ Eigenvalues } \\
\multicolumn{4}{|l}{ Extraction: Principal components } \\
\cline { 2 - 5 } Value & Eigenvalue & $\begin{array}{c}\text { \% Total } \\
\text { variance }\end{array}$ & $\begin{array}{l}\text { Cumulative } \\
\text { Eigenvalue }\end{array}$ & $\begin{array}{c}\text { Cumulative } \\
\%\end{array}$ \\
\hline $\mathbf{1}$ & 1.312197 & 65.60983 & 1.312197 & 65.60983 \\
\hline
\end{tabular}

Figura 20: Número autovalores e \% de explicação para as variáveis analisadas (25 e 33)

Observa-se somente um autovalor explicando $65,60983 \%$ e, fazendo o cálculo das cargas fatoriais, observou-se o que segue na Figura 21.

\begin{tabular}{||l|c|}
\hline \multirow{2}{*}{} & $\begin{array}{l}\text { Factor Loadings } \\
\text { Extraction: Principal components } \\
\text { (Marked loadings are > 700000) }\end{array}$ \\
\cline { 2 - 2 } Variable & $\begin{array}{c}\text { Factor } \\
\mathbf{1}\end{array}$ \\
\hline 25.Você residia: & 0.809999 \\
\hline 33.Você reside: & -0.809999 \\
\hline Expl.Var & 1.312197 \\
\hline Prp.Totl & 0.656098 \\
\hline
\end{tabular}

Figura 21: Cargas fatoriais para as variáveis analisadas (25 e 33)

Pode-se concluir que ambas as cargas fatoriais são significativas. E, aplicando-se o teste dos sinais verifica se houve alteração entre os resultados antes e depois.

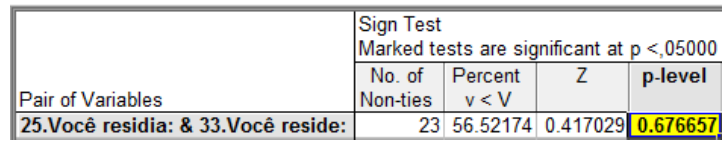

Figura 22: Resultado do teste dos sinais para as variáveis 25 e 33

Como 0,676657 é menor do que o nível de significância adotado $(0,05)$, aceita-se a hipótese nula $\mathrm{H} 0$. Ou seja, não houve alteração nos indivíduos para residir. Portanto, observa-se que a

LEONARDI, João C.; GIORDANI, Estela M. O perfil dos jovens colaboradores para o processo de profissionalização e descentralização da empresa. Revista Saber Humano, Recanto Maestro, n. 3, p. 3567, 2013. 
residência não alterou pelo fato de estarem trabalhando na empresa.

Estabelecendo a análise comparada referente aos valores mais importantes para os jovens colaboradores antes e depois de trabalharem na empresa, podese observar o que segue na Figura 23.

\begin{tabular}{||l|r|r|r|r|}
\hline \multirow{4}{*}{ Value } & \multicolumn{3}{|l|}{$\begin{array}{l}\text { Eigenvalues } \\
\text { Extraction: Principal components }\end{array}$} \\
\cline { 2 - 5 } & Eigenvalue & $\begin{array}{c}\text { \% Total } \\
\text { variance }\end{array}$ & $\begin{array}{l}\text { Cumulative } \\
\text { Eigenvalue }\end{array}$ & $\begin{array}{c}\text { Cumulative } \\
\%\end{array}$ \\
\hline $\mathbf{1}$ & 3.344504 & 33.44504 & 3.344504 & 33.44504 \\
\hline 2 & 1.889840 & 18.89840 & 5.234344 & 52.34344 \\
\hline 3 & 1.324132 & 13.24132 & 6.558477 & 65.58477 \\
\hline
\end{tabular}

Figura 23: Número de autovalores, autovalores e \% de explicação para as variáveis analisadas (26 e 38)

Observa-se dois autovalores explicando $44,90861 \%$. Determinados os autovalores, fez-se o cálculo das cargas fatoriais para cada item e observou-se o que segue na Figura 24.

\begin{tabular}{|c|c|c|c|}
\hline \multirow[b]{2}{*}{ Variable } & \multicolumn{3}{|c|}{$\begin{array}{l}\text { Factor Loadings } \\
\text { Extraction: Principal components } \\
\text { (Marked loadings are }>, 700000 \text { ) }\end{array}$} \\
\hline & $\begin{array}{c}\text { Factor } \\
1\end{array}$ & $\begin{array}{c}\text { Factor } \\
2\end{array}$ & $\begin{array}{c}\text { Factor } \\
3 \\
\end{array}$ \\
\hline 26.1 & 0.085989 & 0.767757 & -0.367684 \\
\hline 26.2 & 0.6 & -0.216066 & -0 . \\
\hline 26.3 & 0 & -0. & 492 \\
\hline 26.4 & 46 & 812 & 0. \\
\hline 26.5 & 40 & 5694 & 0. \\
\hline 38.1 & 81 & 0.844233 & -0.019331 \\
\hline 38.2 & 887 & 104 & 0.178770 \\
\hline 38.3 & 866 & -0.193063 & -0.015550 \\
\hline 38.4 & 0.558326 & -0.074801 & -0.691870 \\
\hline 38.5 & 0.433916 & 0.154519 & 0.785120 \\
\hline Expl.Var & 3.344504 & 1.889840 & 1.324132 \\
\hline Prp.Totl & 0.334450 & 0.188984 & 0.132413 \\
\hline
\end{tabular}

Figura 24: Cargas fatoriais para as variáveis analisadas (26 e 38)

As cargas fatoriais significativas são saúde 38(2) e estudo 38(3) para o Fator 1, indicando respectivamente $\mathrm{e}$ família antes e depois de ingressarem na empresa. Portanto, o valor família permaneceu presente tanto no Fator 1 quanto no Fator 2.
Figura 25:

\begin{tabular}{|c|c|c|c|c|c|}
\hline \multirow[b]{2}{*}{ Variable } & \multicolumn{5}{|c|}{$\begin{array}{l}\text { Friedman ANOVA } \\
\text { ANOVA Chi Sqr. }(\mathrm{N}=29, \mathrm{df}=9)=63,34949 \mathrm{p}=, 00000 \\
\text { Coeff. of Concordance }=, 24272 \text { Aver. rank } \mathrm{r}=, 21567\end{array}$} \\
\hline & $\begin{array}{c}\text { Average } \\
\text { Rank }\end{array}$ & $\begin{array}{l}\text { Sum of } \\
\text { Ranks }\end{array}$ & Mean & Std.Dev. & \\
\hline 26.1 & 3.103448 & 90.0000 & 101.8621 & 1.301761 & \\
\hline 26.2 & 6.620690 & 192.0000 & 105.3103 & 3.381710 & \\
\hline 26.3 & 4.793103 & 139.0000 & 103.5517 & 1.784581 & \\
\hline 26.4 & 6.431034 & 186.5000 & 105.2069 & 3.539363 & \\
\hline 26.5 & 6.396552 & 185.5000 & 105.4138 & 3.122696 & \\
\hline 38.1 & 3.310345 & 96.0000 & 102.1379 & 1.619615 & \\
\hline 38.2 & 6.620690 & 192.0000 & 105.3793 & 2.624252 & \\
\hline 38.3 & 4.879310 & 141.5000 & 103.8966 & 2.410466 & \\
\hline 38.4 & 6.275862 & 182.0000 & 104.8276 & 3.703945 & \\
\hline 38.5 & 6.568966 & 190.5000 & 105.4138 & 2.732310 & \\
\hline
\end{tabular}

Figura 25: Teste de Friedman para as variáveis analisadas (26 e 38)

Como 63,34949 é maior do que o valor tabelado (16,919), aceita-se a hipótese alternativa $\mathrm{H} 1$. Ou seja, houve alteração quanto à importância dos itens avaliados em relação a estudo, saúde e família.

No que se refere ao investimento do tempo antes e depois de ingressar na empresa, observa-se que, conforme a Figura 26, obteve-se quatro autovalores, conforme o que segue:

\begin{tabular}{|l|r|r|r|r|}
\hline \multirow{4}{*}{ Value } & \multicolumn{4}{|l}{$\begin{array}{l}\text { Eigenvalues } \\
\text { Extraction: Principal components }\end{array}$} \\
\cline { 2 - 5 } & Eigenvalue & $\begin{array}{c}\text { \% Total } \\
\text { variance }\end{array}$ & $\begin{array}{l}\text { Cumulative } \\
\text { Eigenvalue }\end{array}$ & $\begin{array}{c}\text { Cumulative } \\
\%\end{array}$ \\
\hline $\mathbf{1}$ & 3.027209 & 30.27209 & 3.027209 & 30.27209 \\
\hline 2 & 1.740860 & 17.40860 & 4.768069 & 47.68069 \\
\hline 3 & 1.438118 & 14.38118 & 6.206188 & 62.06188 \\
\hline 4 & 1.050310 & 10.50310 & 7.256498 & 72.56498 \\
& & & & \\
\hline
\end{tabular}

Figura 26: Número autovalores e \% de explicação para as variáveis analisadas (27 e 39)

Fazendo o cálculo dos componentes principais, pode-se evidenciar que apenas foi significativo, no Fator 1, o item 39.4, ou seja, estudar.

LEONARDI, João C.; GIORDANI, Estela M. O perfil dos jovens colaboradores para o processo de profissionalização e descentralização da empresa. Revista Saber Humano, Recanto Maestro, n. 3, p. 3567, 2013. 


\begin{tabular}{|c|c|c|c|c|}
\hline \multirow[b]{2}{*}{ Variable } & \multicolumn{4}{|c|}{\begin{tabular}{|l|} 
Factor Loadings \\
Extraction: Principal components \\
(Marked loadings are $>, 700000$ )
\end{tabular}} \\
\hline & $\begin{array}{c}\text { Factor } \\
1\end{array}$ & $\begin{array}{c}\text { Factor } \\
2 \\
\end{array}$ & $\begin{array}{c}\text { Factor } \\
3 \\
\end{array}$ & $\begin{array}{c}\text { Factor } \\
4\end{array}$ \\
\hline 27.1 & -0.490212 & -0.284889 & -0.637178 & 0.282191 \\
\hline 27.2 & -0.193285 & 0.656442 & -0.307937 & 0.216090 \\
\hline 27.3 & -0.402538 & 0.487103 & 0.406593 & -0.396163 \\
\hline 27.4 & -0.671999 & -0.341108 & 0.063146 & 0.377034 \\
\hline 27.5 & -0.554747 & 0.523220 & 0.197139 & 0.415119 \\
\hline 39.1 & -0.538227 & 0.268753 & -0.654056 & -0.318453 \\
\hline 39.2 & -0.664484 & -0.272448 & -0.027930 & -0.567181 \\
\hline 39.3 & -0.168749 & -0.630637 & 0.202310 & 0.087053 \\
\hline 39.4 & -0.835868 & -0.207766 & 0.107667 & -0.062468 \\
\hline 39.5 & -0.608112 & 0.118629 & 0.498033 & 0.134063 \\
\hline Expl.Var & 3.027209 & 1.740860 & 1.438118 & 1.1 .050310 \\
\hline Prp.Totl & 0.302721 & 0.174086 & 0.143812 & 0.105031 \\
\hline
\end{tabular}

Figura 29: Cargas fatoriais para as variáveis analisadas (27 e 39)

Fazendo o cálculo das cargas fatoriais para estabelecer o grau de significância delas, observa-se, na Figura 28, que apenas a variável família (39.4) é significativa para o fator 1 .

\begin{tabular}{|c|c|c|c|c|c|}
\hline \multirow[b]{2}{*}{ Variable } & \multicolumn{5}{|c|}{$\begin{array}{l}\text { Friedman ANOVA } \\
\text { ANOVA Chi Sqr. }(\mathrm{N}=29, \mathrm{df}=9)=49,33114 \mathrm{p}=, 00000 \\
\text { Coeff. of Concordance }=, 18901 \text { Aver. rank } r=, 16004\end{array}$} \\
\hline & \begin{tabular}{|c|} 
Average \\
Rank
\end{tabular} & $\begin{array}{r}\text { Sum of } \\
\text { Ranks }\end{array}$ & Mean & Std.Dev. & \\
\hline 27.1 & 3.586207 & 104.0000 & 102.6897 & 1.965841 & \\
\hline 27.2 & 4.844828 & 140.5000 & 103.5517 & 1.784581 & \\
\hline 27.3 & 5.379310 & 156.0000 & 103.8966 & 2.380649 & \\
\hline 27.4 & 7.741379 & 224.5000 & 106.1034 & 3.166170 & \\
\hline 27.5 & 5.827586 & 169.0000 & 104.6207 & 2.691439 & \\
\hline 39.1 & 3.620690 & 105.0000 & 102.5517 & 1.660168 & \\
\hline 39.2 & 6.137931 & 178.0000 & 104.3448 & 1.818081 & \\
\hline 39.3 & 6.172414 & 179.0000 & 104.8621 & 2.862618 & \\
\hline 39.4 & 5.724138 & 166.0000 & 104.4828 & 2.443953 & \\
\hline 39.5 & 5.965517 & 173.0000 & 104.9310 & 3.272516 & \\
\hline
\end{tabular}

Figura 28: Resultado do Teste de Friedman para as variáveis analisadas (27 e 39$)$

Como 49,33114 é maior do que o valor tabelado (16,919), aceita-se a hipótese alternativa $\mathrm{H} 1$. Ou seja, houve alteração quanto a ordem de importância atribuída nas atividades em que mais tempo é investido em relação à família.

No que se refere à análise das atitudes que os jovens consideravam mais significativas em sua vida antes e depois (questões 28 e 40) de ingressar na empresa, conforme o grau de importância atribuído, pode-se observar que se obteve quatro autovalores.

\begin{tabular}{|l|r|r|r|r}
\hline \multirow{4}{*}{ Value } & \multicolumn{4}{|l}{$\begin{array}{l}\text { Eigenvalues } \\
\text { Extraction: Principal components }\end{array}$} \\
\cline { 2 - 5 } & Eigenvalue & $\begin{array}{c}\text { \% Total } \\
\text { variance }\end{array}$ & $\begin{array}{l}\text { Cumulative } \\
\text { Eigenvalue }\end{array}$ & $\begin{array}{c}\text { Cumulative } \\
\%\end{array}$ \\
\hline $\mathbf{1}$ & 3.555553 & 35.55553 & 3.555553 & 35.55553 \\
\hline 2 & 1.550256 & 15.50256 & 5.105809 & 51.05809 \\
\hline 3 & 1.275117 & 12.75117 & 6.380926 & 63.80926 \\
\hline 4 & 1.191551 & 11.91551 & 7.572477 & 75.72477 \\
\hline
\end{tabular}

Figura 29: Número autovalores e \% de explicação para as

variáveis analisadas (28 e 40)

Partindo disso, realizou-se o cálculo dos componentes principais para identificar as variáveis com maior significância em relação aos fatores, conforme Figura 30.

\begin{tabular}{|c|c|c|c|c|}
\hline \multirow[b]{2}{*}{ Variable } & \multicolumn{4}{|c|}{$\begin{array}{l}\text { Factor Loadings } \\
\text { Extraction: Principal components } \\
\text { (Marked loadings are }>, 700000 \text { ) }\end{array}$} \\
\hline & $\begin{array}{c}\text { Factor } \\
1\end{array}$ & $\begin{array}{c}\text { Factor } \\
2\end{array}$ & $\begin{array}{c}\text { Factor } \\
3\end{array}$ & $\begin{array}{c}\text { Factor } \\
4\end{array}$ \\
\hline 28.1 & -0.696002 & 0.423922 & 0.065111 & -0.338734 \\
\hline 28.2 & -0.537451 & -0.052741 & -0.246956 & -0.674847 \\
\hline 28.3 & -0.375375 & -0.697480 & 0.347059 & -0.272953 \\
\hline 28.4 & -0.504886 & -0.620659 & -0.095279 & 0.023597 \\
\hline 28.5 & -0.530005 & 0.065280 & -0.387455 & 0.551302 \\
\hline 40.1 & -0.730678 & 0.127822 & 0.348748 & 0.294852 \\
\hline 40.2 & -0.557033 & 0.595730 & 0.167852 & -0.223998 \\
\hline 40.3 & -0.773870 & 0.135988 & -0.172803 & 0.234326 \\
\hline 40.4 & -0.700323 & -0.244793 & 0.437267 & 0.215456 \\
\hline 40.5 & -0.414796 & -0.205323 & -0.747916 & -0.062884 \\
\hline Expl.Var & 3.555553 & $=1.550256$ & 101.275117 & 1.191551 \\
\hline Prp.Totl & 0.355555 & 0.155026 & 0.127512 & 0.119155 \\
\hline
\end{tabular}

Figura 30: Cargas fatoriais para as variáveis analisadas (28 e 40)

Observa-se na figura 31 que para o fator 1 houveram 3 variáveis significativas, ou seja, honestidade (40.1), comprometimento (40.3) e disciplina (40.4). Para o fator 2 não existiu nenhuma variável significativa e para o fator 3 observa-se a variável 40.5 , ou seja, ética e persistência.

LEONARDI, João C.; GIORDANI, Estela M. O perfil dos jovens colaboradores para o processo de profissionalização e descentralização da empresa. Revista Saber Humano, Recanto Maestro, n. 3, p. 3567, 2013. 


\begin{tabular}{|c|c|c|c|c|c|}
\hline \multirow[b]{2}{*}{ Variable } & \multicolumn{5}{|c|}{$\begin{array}{l}\text { Friedman ANOVA } \\
\text { ANOVA Chi Sqr. }(\mathrm{N}=29, \mathrm{df}=9)=38,71212 \mathrm{p}=, 00001 \\
\text { Coeff. of Concordance }=, 14832 \text { Aver. rank } \mathrm{r}=, 11791\end{array}$} \\
\hline & \begin{tabular}{|c|}
$\begin{array}{c}\text { Average } \\
\text { Rank }\end{array}$ \\
\end{tabular} & $\begin{array}{l}\text { Sum of } \\
\text { Ranks }\end{array}$ & Mean & Std.Dev. & \\
\hline 28.1 & 3.431034 & 99.5000 & 103.3103 & 2.172942 & \\
\hline 28.2 & 5.103448 & 148.0000 & 104.5862 & 2.353072 & \\
\hline 28.3 & 6.482759 & 188.0000 & 105.8621 & 3.719871 & \\
\hline 28.4 & 5.862069 & 170.0000 & 105.6207 & 2.624252 & \\
\hline 28.5 & 5.982759 & 173.5000 & 105.2759 & 3.127031 & \\
\hline 40.1 & 5.465517 & 158.5000 & 104.6897 & 3.152136 & \\
\hline 40.2 & 3.827586 & 111.0000 & 103.6207 & 2.274294 & \\
\hline 40.3 & 6.396552 & 185.5000 & 105.6207 & 2.664767 & \\
\hline 40.4 & 6.551724 & 190.0000 & 106.0690 & 3.769530 & \\
\hline 40.5 & 5.896552 & 171.0000 & 105.5862 & 2.860035 & \\
\hline
\end{tabular}

Figura 31: Resultado do Teste de Friedman para as variáveis analisadas (28 e 40)

Como 38,71212 é maior do que o valor tabelado $(16,919)$, aceita-se a hipótese alternativa $\mathrm{H} 1$. Ou seja, houve alteração quanto à ordem de importância atribuída nas atitudes mais importantes na vida.

Além da análise estatística multivariada das questões fechadas do questionário, procedeu-se a análise de conteúdo das questões abertas.

\section{Os jovens e a visão da empresa}

Para avaliar a percepção dos jovens em relação a como veem a empresa, algumas das questões foram realizadas em formato aberto a fim de possibilitar a expressão mais livre dos jovens pesquisados. Tais questões a seguir analisadas foram relativas à: 1) percepção de seu aprimoramento; 2) como os clientes veem a empresa; 3 ) visão do que é ser líder e 4) modelo de gestão da empresa.

Os jovens identificam desafios pessoais referentes ao aprimoramento pessoal em alguns comportamentos tais como: maior paciência e autoconfiança, menor ansiedade, timidez e menos detalhista, desenvolvimento pessoal e melhorar os relacionamentos. Cotam também algumas habilidades como: melhorar aprendizado, ter mais visão de empreendedor, conhecimento técnico, melhorar técnicas gerenciais com estudo e aplicação prática, gestão de pessoas, conhecer mais e ser mais político, mostrar mais pontos positivos realizados, melhorar a comunicação, experiência em préfabricado. E, por fim, apontam a necessidade de adquirir conhecimentos, citaram os jovens: estudar e concluir a graduação e certificação Microsoft, inglês, gestão de projetos, qualidade, saúde, segurança e meio ambiente, aplicar o conhecimento de engenharia civil na Logística, estudar mais e influenciar opiniões, posicionar-se melhor, aumentar a pró-atividade.

Destes elementos citados pelos jovens, pode-se compreender que a equipe de fato identifica a necessidade de aprimoramento em principalmente duas dimensões: o aprimoramento técnico de seu trabalho e o desenvolvimento pessoal. Portanto, existe na empresa um contexto no qual propicie a implementação de um programa de formação life long learning, conforme o desejo dos líderes.

Considerando a visão dos jovens a vêem, evidenciou-se que os jovens levantaram pontos fortes e fracos. Os pontos fortes foram sistematizados em três grandes temas assim distribuídos: a) características confiança: idônea, segura, sólida, tradicional, credibilidade e em crescimento; b) característica de qualidade nos serviços: bom atendimento, séria e bem estruturada (porém cara), pessoas capacitadas, solução construtiva, comprometida com prazo e escopo, preparado para o mercado, ótima empresa, atende as expectativas, capacitada e pensa no bem estar de seus clientes e funcionários; c) característica da empresa: potente, forte, corajosa, influencia pessoas, bom custo benefício, qualidade, bom produto, responsável, atende as expectativas, potencial, profissional, capacitada, transparência, fácil acesso, grande, comprometida, forte, possuir singeleza e maestria de desenvolver habilidades, ideias e

LEONARDI, João C.; GIORDANI, Estela M. O perfil dos jovens colaboradores para o processo de profissionalização e descentralização da empresa. Revista Saber Humano, Recanto Maestro, n. 3, p. 3567, 2013. 
pensamento à um bem comum, atraente, potencial.

Em relação aos aspectos a melhorar os jovens identificam: preços elevados, preço acima do mercado, profissionais não atendem $100 \%$ os resultados, melhorar o pós-vendas, tradicional, deficiente na qualidade do produto, custos elevados, cara, dificuldades de administrar o prazo.

Pode-se analisar destas respostas que os jovens avaliam positivamente a empresa e a consideram com um bom potencial, também acreditam que os clientes tem a empresa em alto valor. Essa confiança que os jovens depositam na empresa é fundamental para que se invista neles, ou seja, formá-los para profissionalizar a empresa e assim ingressar em um patamar mais elevado que o atual.

Desta avaliação pode-se perceber que os aspectos positivos são muito mais ressaltados do que os aspectos que precisam ser melhorados e que muitos dos quesitos que identificam a necessidade da mudança estão relacionadas às questões técnicas em relação a formação dos jovens para qualificar a sua atividade profissional.

As respostas que os jovens deram sobre o que é ser um líder foram classificadas conforme três grandes temas descritos a seguir: a) ser exemplo: ser o primeiro a servir, estaralinhado à ideologia da empresa para agir e instruir a equipe, ser exemplo aos outros, influenciar pessoas, ser referência, ser exemplo aos demais quanto a conhecimento, ética, comprometimento, responsabilidade e outras; b) gerir pessoas: gerar resultados através das pessoas, criar condições para as pessoas exercerem todo seu potencial, gerar autoconfiança, estimular perseguirem um ideal, agregar valores pessoais e profissionais para o liderado, é mobilizar pessoas à sua volta a crer num objetivo e trabalhar nele, é ter a confiança admiração das pessoas pela sua forma de conduzir a vida, capacidade de influenciar pessoas e outras; c) características pessoais e atitudes: saber ouvir e se comunicar, capacidade de conduzir as pessoas ao objetivo a vitória, manter o foco, saber ouvir, administrar a vida e não o tempo que continua aprendendo a liderar, obter sucesso por meio de relacionamentos, que sabe abrir mão para conquistar, capacidade de administrar pessoas diferentes, conduzindo-as a objetivos comuns, influenciar pessoas, interagir com todos da equipe, e buscar descobrir quais são suas qualidade e defeitos, auto gestão conhecimento e sabedoria em administrar responsabilidades e pessoas e outras.

As respostas foram bem extensas e demonstram que o grupo de jovens possui uma compreensão e capacidade de reconhecimento de sua liderança dentro da empresa. Essa característica destes jovens é muito importante pois também confirma a condição propícia da empresa profissionalizar-se e descentralizar a sua gestão.

E, por fim, em relação à gestão da empresa, sobre a posição em relação ao melhor sistema de gestão e como deveria ser realizada, os jovens manifestaram-se conforme segue a Figura 32.

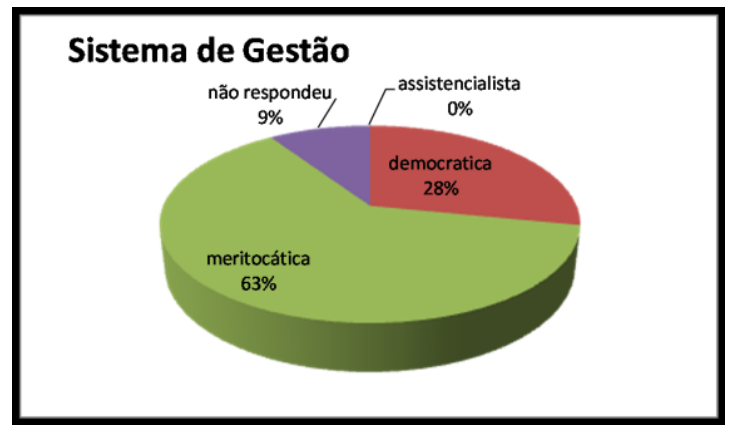

Figura 32: Percepção sobre o sistema de gestão

No que se refere ao sistema de gestão, os jovens manifestam a preferência pela meritocracia (63\%), $28 \%$ considera melhor a democracia, e nenhum considerou a opção assistencialista e $9 \%$ não respondeu. Portanto, nota-se que este

LEONARDI, João C.; GIORDANI, Estela M. O perfil dos jovens colaboradores para o processo de profissionalização e descentralização da empresa. Revista Saber Humano, Recanto Maestro, n. 3, p. 3567, 2013. 
indicador também aponta positivamente para implementação de mudanças na gestão da empresa.

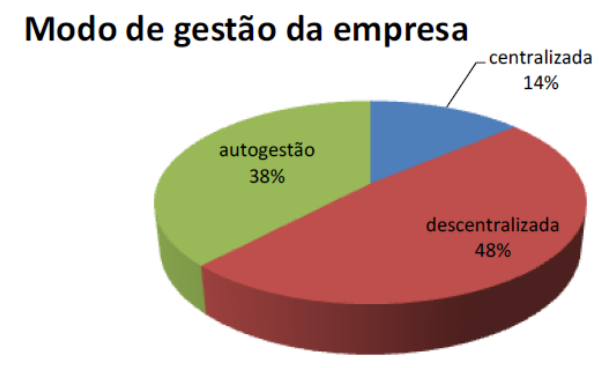

Figura 33: Modo de gestão da empresa

Em relação ao modo de gestão, pode-se observar a tendência em descentralizar (48\%) e se autogerir $(38 \%)$, apenas $14 \%$ entende que deve ser de modo centralizado. Isso indica que existe um contexto propício para projetar mudanças em seu sistema de gestão.

\section{Relação com o trabalho}

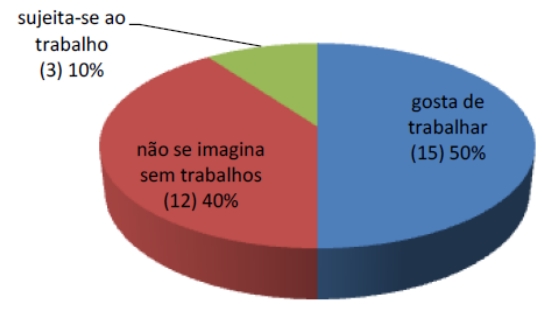

Figura 34: Relação com o trabalho

A relação da pessoa com o trabalho é de fundamental importância e, neste caso, pode-se perceber se existe identidade de valores com a filosofia da empresa e com os valores dos jovens. Conforme expressam os jovens, 50\% deles gosta de trabalhar e $40 \%$ deles não se imagina sem trabalhar. Isso demonstra um potencial ativo, ou seja, os jovens demonstram-se abertos e em disponibilidade para aplicar o princípio do saber servir e aprimorar-se em seu profissionalismo. E, segundo Meneghetti (2008, 2009) líder é aquele que sabe servir.
Contudo, $10 \%$ dos pesquisados revelam que o trabalho é algo a se sujeitar, indicando que esses não se adequariam às mudanças esperadas pelos líderes da empresa.

Por fim, os dados da pesquisa revelam que os jovens estão em identidade e utilitarismo funcional com a empresa e desta forma, demonstra que a empresa possui uma base sólida de colaboradores jovens para investir no processo de profissionalização e de descentralização de sua gestão.

\section{Considerações Finais}

As mudanças que são necessárias para a consolidação e profissionalização de uma empresa parecem revolucionárias e muito difíceis, mas na verdade derivam de processos de decisões e ações que a empresa vai construindo e corrigindo continuamente. Sob as condições apropriadas as mudanças se efetivam, mas dependem muito de como as pessoas as percebem. Esta pesquisa objetivou responder a seguinte questão: será que a empresa possui uma equipe de jovens que está em identidade e utilitarismo funcional com o escopo das mudanças da forma de gestão e de profissionalização?

Buscar o processo de profissionalização da empresa requer do líder maturidade, desprendimento e principalmente apostar em mudanças partindo da utilização do capital humano que possui disponível. Assim, conhecer o perfil do colaborador e compreender a tendência que este indica pode ser um primeiro passo para o início das transformações que se deseja implementar. Conforme Collins (2010), algumas empresas experimentam logo no seu início um grande sucesso que é alimentado pela criatividade, por movimentos ousados e empreendedorismo visionário. À medida que estas empresas crescem, tornam-se mais complexas e começam a tropeçar em seu próprio

LEONARDI, João C.; GIORDANI, Estela M. O perfil dos jovens colaboradores para o processo de profissionalização e descentralização da empresa. Revista Saber Humano, Recanto Maestro, n. 3, p. 3567, 2013. 
sucesso: excesso de gente nova, de novos clientes, de novos pedidos e de novos produtos. Começam a aparecer problemas em vários setores como, por exemplo, com os clientes, no fluxo de caixa e nos cronogramas. Como reação, se contrata mais gente e se aperfeiçoam os processos e procedimentos. O que antes era um ambiente igualitário torna-se uma estrutura hierárquica e burocratizada com relações de autoridade, privilégios e segmentações que colocam ordem no caos, mas matam o espírito empreendedor. Como consequência, pessoas inovadoras deixam a empresa, a criatividade desaparece e a mediocridade reina.

Por isso, esta pesquisa buscou enfrentar a problemática de identificar o potencial humano jovem que a empresa possui a fim de perceber se existe a prédisposição para implementar mudanças em sua gestão, o que requer investimento em profissionalização na equipe de colaboradores. Partindo de estudos realizados a respeito da relação do jovem com o trabalho, compreendeu-se a importância de programas de formação continuada na empresa - life long learning - a fim de poder projetá-la num patamar de renovação constante e assim, um progressivo crescimento.

Ter as pessoas certas tem mais a ver com talentos inatos e caráter das pessoas do que com experiências ou habilidades específicas. Elas precisam ser ensinadas e orientadas, mas não precisam ser excessivamente controladas ou motivadas, pois são os indivíduos que devem posicionara-se e colocar em ação a sua vontade em se desenvolver. Gastar energia tentando motivar, normalmente é perda de tempo. Quando se tem as pessoas certas, a verdadeira questão é como não desmotivá-las, e deixar as pessoas erradas é injusto com as pessoas certas, que acabam tendo que compensar as inadequações geradas e acabam se frustrando.
Com as transformações ocorridas no mercado de trabalho, os autores Meneghetti (2007, 2010), Morin, Tonelli e Pliopas (2007), Aguiar e Ozella (2006), Borges e Coutinho (2010) argumentam que o trabalho quando, adquire sentido para o jovem, pode por ele ser desenvolvido. $\mathrm{O}$ trabalho não apenas como o suprimento de uma necessidade básica de autossustento, visto que é prioritário e elementar, mas ele pode levar o jovem à realização de seu potencial criativo. Contudo, depende de como a empresa e o jovem escolhem o seu estilo de vida e a realização de sua relação com o trabalho. Meneghettti (2010) sugere que este estilo seja exercido continuamente e com a finalidade de colocar a mente a apreender com a escola do real, com a vida, aprendendo as coisas tais como são e não como o jovem imagina ou projeta.

Considerando estes fundamentos, a pesquisa dedicou-se a identificar como os jovens se posicionavam e como os jovens são em relação ao seu trabalho na atual empresa. Com a pesquisa de campo, realizada por meio de questionário autoaplicativo, e aplicando a análise estatística multivariada para as questões fechadas, obteve-se que:

1) Em relação à história de vida, conforme a análise estatística dos componentes principais destes jovens foi significativo que, em sua maioria, as mães possuem escolarização de ensino superior e algumas inclusive são especialistas;

2) Antes de trabalhar na empresa, os jovens possuíam hábito de ocupar seu tempo com internet e televisão;

3) Em relação às atitudes que possuíam, identificou-se o comprometimento e a determinação.

LEONARDI, João C.; GIORDANI, Estela M. O perfil dos jovens colaboradores para o processo de profissionalização e descentralização da empresa. Revista Saber Humano, Recanto Maestro, n. 3, p. 3567, 2013. 
Nas questões em que foram realizadas a comparação entre antes e depois de trabalharem na empresa, o indicador estudado demonstrou alteração, aumentando o interesse. Os fatores mais importantes são a saúde, o estudo e a família. Pode-se destacar que o trabalho, importante valor não fez parte das indicações dos jovens. Esse aspecto é importante, uma vez que é por meio do trabalho que o jovem se desenvolve. Porém, nas respostas em relação a essa questão específica o trabalho foi considerado de fundamental importância. Contudo, na relação com os demais aspectos ele ficou relativizado. Portanto, esse ainda é um aspecto que deve ser considerado e verificado tendo em vista os objetivos de profissionalizar e descentralizar a gestão da empresa.

Considerando as atitudes que identificam antes e depois de ingressarem na empresa, pode-se ressaltar a honestidade, o comprometimento e a disciplina; também se destacam as variáveis ética e persistência, pois obtiveram índices significativos de mais de $50 \%$ dos pesos explicativos.

Investigados sobre o seu aprimoramento, os jovens atribuem importância à dimensão profissional e pessoal e, sobre a percepção do que os clientes pensam a respeito da empresa, percebeu-se que estes possuem uma visão positiva e que apontam alguns limites. A visão que possuem sobre ser líder demonstra três grandes questões: a dimensão pessoal, a dimensão da formação e, principalmente, atitudes e habilidades de formar, aglutinar e liderar pessoas.

Indagados sobre a gestão da empresa, os jovens demonstram preferência pela meritocracia e pelo sistema descentralizado. Os jovens manifestam gostar de trabalhar na empresa e, com isso, pode-se confirmar que existe indícios de identidade dos colaboradores com o modo de pensar e agir dela. Assim, investigando as diferentes variáveis, pode-se concluir que a equipe jovem possui potencial para implementar o programa de formação continuada que sustenta as transformações desejadas de profissionalização e de renovação organizacional. $\mathrm{O}$ investimento nos talentos, que existem por meio da formação de tipo life long learning e, tendo como suporte a pedagogia ontopsicológica para a formação do jovem, podem consolidar as transformações conforme o critério do desenvolvimento humano, visto que, esse é a garantia de evolução e crescimento integral para todos (MENEGHETTI, 2008).

Portanto, pode-se dizer que foram confirmadas as hipóteses de trabalho desta pesquisa. A pesquisa revelou que é fundamental conhecer mais profundamente os colaboradores jovens, pois, são eles que, com seu profissionalismo e desenvolvimento pessoal, encontram a sua realização na empresa conforme atuam a identidade do líder. Elementar é a formação continuada, e a equipe jovem demonstrou gosto pelo estudo e com a compreensão de que a gestão meritocrática e descentralizada podem ser instituídas. Percebe-se, também, que o grupo de colaboradores possui características que indicam identidade com a empresa, e por isso, o potencial de mudanças pode ser considerado inicialmente propício e adequado.

Investir no próprio business, conhecendo os valores humanos existentes nele, é a contribuição principal desta investigação, pois ela possibilitou formar uma imagem mais próxima da realidade cotidiana que nem sempre se consegue colher.

LEONARDI, João C.; GIORDANI, Estela M. O perfil dos jovens colaboradores para o processo de profissionalização e descentralização da empresa. Revista Saber Humano, Recanto Maestro, n. 3, p. 3567, 2013. 


\section{Referências}

AGUIAR, W. M. J. \& OZELLA, S. Núcleos de significação como instrumento para a apreensão da constituição dos sentidos. Psicologia Ciência e Profissão, n. 26, p. 222-245, 2006.

ARGENTA, R. Cultura Organizacional do Business Intuition e Competência Competitiva. Tese de Especialização Profissional em Psicologia, com abordagem em Ontopsicologia Social. Cátedra de Ontopsicologia. Faculdade de Psicologia. Universidade Estatal de São Petersburgo, 2011.

BAGGIO, L. e SCHUTEL, S. Trajetória empresarial e intuição: o case do nascimento, desenvolvimento e evolução de uma indústria textil de tapeçaria. 2010. 34 f. Monografia de Especialização (MBA Business Intuition) Faculdade Antonio Meneghetti.

BARBIERI, J. L'impresa come contraddizione del leader. In: AUTORI VARI. Atti $1^{\circ}$ Congresso Mondiale XV Internazionale di Ontopsicologia. Mosca (RU): Psicologica Editrice, 8 a 12 ott, 1998.

BARDIN, L. Análise de conteúdo. Lisboa: Edições 70, 1977.

BORGES, R. C. P. e COUTINHO, M. C. Trajetórias Juvenis: significando projetos de vida a partir do primeiro emprego. Revista Brasileira de Orientação Profissional. V.11, n.2, p. 189-200, 2010 .

CÂMARA, S. G. e SARRIERA, J. C. Critérios de seleção para o trabalho de adolescentes-jovens: perspectivas dos empregadores. Revista Psicologia em Estudo. V6, n1, Maringá, p. 77-84, 2001.

CAMPOMAR, M. C. Do uso de "estudo de caso" em pesquisas para dissertações e teses em administração. Revista de Administração, São Paulo, v.26, n.3, p. 95-97, julho/setembro 1991.

CHIESI, A. e MARTINELLI, A. O trabalho como escolha e oportunidade. Revista Brasileira de Educação. n.5, p. 110-125, 1997.

COLLINS, J. Empresas feitas para vencer. 18a. ed. São Paulo: Elsevier, 2010.

COMISSÃO DAS COMUNIDADES EUROPEIAS. Documento de Trabalho dos Serviços da Comissão. Memorando sobre Aprendizagem ao Longo da Vida Bruxelas, 30.10.2000.
DELORS, J. et al. Os quatro pilares da educação (p. 89-102). In: DELORS, Jacques et al. Educação um tesouro a descobrir: Relatório para a Unesco da Comissão Internacional sobre Educação para o séc. XXI. 5a. ed. São Paulo, Cortez; Brasília, DF, MEC, UNESCO, 2001.

FOLETTO, A. Ontopsicologia e Humanização das relações de trabalho no campo. Tese de Especialização Profissional em Psicologia, com abordagem em Ontopsicologia Social. Cátedra de Ontopsicologia. Faculdade de Psicologia. Universidade Estatal de São Petersburgo, 2011.

GUIMARÃES, N. A. Trabalho: uma categoriachave no imaginário juvenil? In: Abramo, Helena Wendel e Branco, Pedro Paulo Martoni (Orgs.). Retratos da Juventude Brasileira [título provisório], São Paulo, Instituto Cidadania e Editora da Fundação Perseu Abramo, 2004.

HACKMAN, J. R., \& OLDHAM, G.R. Motivation thorough the design of work: Tes ot a theory. Organizational Behavior and Human Performance. n.16, 250-279, 1976.

HAIR, J. F.Jr. Fundamentos de Métodos de Pesquisa Em Administração. Porto Alegre: ArtMed, 2007.

MARTINS, H. H. T. de S. O jovem no mercado de trabalho. Revista Brasileira de Educação. n. 5, p. 96-109, 1997.

McGREGOR, D. O lado humano da empresa. Tradução Margarida Maria C. Oliva. 3a. ed. São Paulo: Martins Fontes, 1999.

MENEGHETTI, A. Pedagogia ontopsicológica. 2a.ed. Recanto Maestro: Ontopsicologia Editrice, 2005.

MENEGHETTI, A. Aprendiz Líder. São Paulo: FOIL, 2009.

MENEGHeTti, A. Psicologia do Líder. Recanto Maestro: OntoEd, 2008.

MENEGHETTI, A. Psicologia Impresariale. Marudo-Itália: FOIL, 2010.

MENEGHETTI, A. A arte de viver dos sábios. Florianopolis: OntoEd, 2003.

MENEGHETTI, A. Psicologia Managerial. São Paulo: FOIL, 2007.

MORIN, E. Os sentidos do trabalho. In T. Wood (Ed.) Gestão empresarial: $O$ fator humano. São Paulo, SP: Atlas, p. 13-34, 2002.

LEONARDI, João C.; GIORDANI, Estela M. O perfil dos jovens colaboradores para o processo de profissionalização e descentralização da empresa. Revista Saber Humano, Recanto Maestro, n. 3, p. 3567, 2013. 
MORIN, E.; TONELLI M. J. e PLIOPAS, A. L. V. O trabalho e seus sentidos. Revista Psicologia \& Sociedade, n.19, p. 47-56, 2007.

PAIS, J. M. Emprego juvenil e mudança social: velhas teses, novos modos de vida. Rev. Análise Social, Lisboa, 1991, p. 945-987.

PELLEGRINI, B. M.; PETRY, A. M.; SCHUTEL, S. A liderança na terceira idade: o sentido do trabalho. Revista Saber Humano, Recanto Maestro, n. 1, p. 10-20, fev. 2011.

PREGADIER, A. P. M.; BARBIERI, J. Residence de autenticação: relação entre conceituação e exercício do autossustento em jovens. Revista Saber Humano, Recanto Maestro, n. 1, p. 105 113, fev. 2011.

ROCHA, S. A inserção dos jovens no mercado de trabalho. Caderno CRH. V.11, n. 54, Salvador, p. 533-550, 2008.

SCHIESSL, C. S. e SARRIERA, J. C. Refletindo a questão do ingresso ao Ensino Superior: dificuldades e expectativas dos jovens de Ensino Médio. In: SARRIERA, J.C. et. al. Desafios do mundo do trabalho: orientação, inserção e mudanças. Porto Alegre: EDIPUCRS, 2004.

TEIXEIRA, M. A. P. e GOMES, W. B. Estou me formando... E agora? Reflexões e Perspectivas de Jovens Formados Universitários. Revista Brasileira de Orientação Profissional, v.5, p. 47 62, 2004.

VIGOTSKI, L. S. Pensamiento y palabra. In: L. S. Vigotski. Obras Escogidas. Madrid: Visor Distribuiciones, v.2, p. 287-348, 1992.
SCHAEFER, Marina Helena Sewald. A Formação Jovem e o Mercado de Trabalho. Antonio Menenghetti Faculdade. Curso Graduação em Administração. Trabalho de Conclusão de Curso. 2011.

KIDDER, L. H. (org.). Métodos de pesquisa nas relações sociais. Medidas de Pesquisa em Ciências Sociais. Vol 2. São Paulo: E.P.U., 1987.

Autores:

João Carlos Leonardi: engenheiro civil, empresário, Diretora na Leonardi Construção Industrializada Ltda., pós-graduado em MBA O Empreendedor e a Cultura Humanista, cursando Especialização em Gestão do Conhecimento e o Paradigma Ontopsicológico (AMF) e cursando Especialização em Psicologia com abordagem em Ontopsicologia pela Universidade Estatal de São Petersburgo-Rússia.

Estela Maris Giordani: pedagoga, professora universitária na Universidade Federal de Santa Maria (UFSM), pesquisadora e professora convidada da graduação e pós-graduação da Faculdade Antonio Meneghetti; Mestre em Educação (UFRGS), Doutora em Educação (UNICAMP), Especialista em Psicologia com abordagem em Ontopsicologia pela Universidade Estatal de São Petersburgo-Rússia.

Submetido em: 30/04/2013

Aceito em: 13/06/2013

LEONARDI, João C.; GIORDANI, Estela M. O perfil dos jovens colaboradores para o processo de profissionalização e descentralização da empresa. Revista Saber Humano, Recanto Maestro, n. 3, p. 3567, 2013. 